Document downloaded from:

http://hdl.handle.net/10251/122520

This paper must be cited as:

Galindo, J.; Guardiola, C.; Dolz, V.; Kleut, P. (2018). Further analysis of a compressionexpansion machine for a Brayton Waste Heat Recovery cycle on an IC engine. Applied Thermal Engineering. 128:345-356. https://doi.org/10.1016/j.applthermaleng.2017.09.012

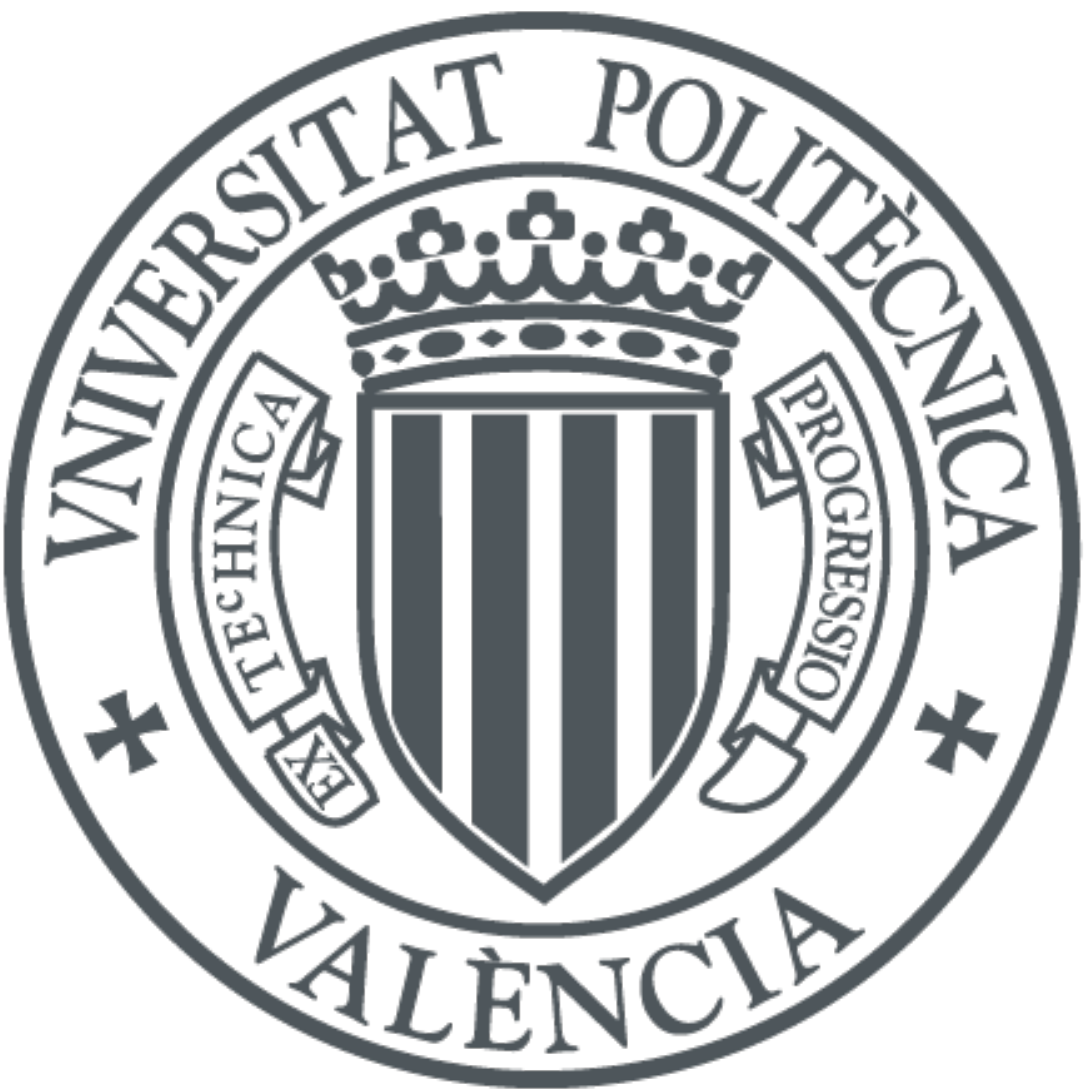

The final publication is available at

https://doi.org/10.1016/j.applthermaleng.2017.09.012

Copyright Elsevier

Additional Information 


\title{
Further analysis of a compression-expansion machine for a Brayton Waste Heat Recovery cycle on an IC engine
}

\author{
J. Galindo ${ }^{a}$; C. Guardiola ${ }^{b}$ V. Dolz $;$ P. Kleut ${ }^{d}$ \\ a,b,c,d CMT - Motores Térmicos \\ Universitat Politècnica de València, 46022 Camino de Vera s/n, Valencia, Spain \\ a Email: galindo@mot.upv.es \\ b Email: carguaga@mot.upv.es \\ ${ }^{c}$ Email: vidolrui@mot.upv.es \\ ${ }^{\mathrm{d}}$ Email: pek1@mot.upv.es
}

In order to comply with the legislation, car manufacturers are looking for a way to lower the $\mathrm{CO}_{2}$ emission by improving engine efficiency. About one third of the fuel combustion energy is wasted through exhaust gasses. Waste Heat Recovery (WHR) could improve engine efficiency by recovering a part of exhaust gasses energy. In this study, the potential use of an open loop Brayton cycle with a volumetric compression expansion machine for exhaust gas waste heat recovery was investigated. The use of the Brayton cycle system with only two main elements, a heat exchanger and a volumetric machine, could be very interesting due to its compactness and versatility. However, the publications on this subject are scarce. The present paper aims at bridging this knowledge gap by studying the cycle viability for passenger car application characterized by low temperatures, variable working conditions and several restrictions of available space and weight. The simulated vehicle was a Ford Mondeo family car with an Ecoboost 2.0 engine. The main components of the Brayton cycle WHR system model were a heat exchanger and an alternating piston machine that was used both as a compressor and as an expander. Theoretical studies were conducted in the compression-expansion machine model in order to determine the main parameters that influence the cycle and optimise those parameters in order to obtain the maximum recuperated power. The conclusion was that the cycle viability is not clear because cycle losses are in the same order of magnitude as the recuperated power. Considering future improvements of the compressionexpansion machine and the heat exchanger, the recuperated power could be positive. Nevertheless, it is hard to expect that recuperated power would be sufficient to justify the application of this WHR system in the vehicle.

Keywords: Brayton cycle, Waste Heat Recovery, WHR, Internal Combustion Engine 


\begin{tabular}{|c|c|}
\hline \multicolumn{2}{|c|}{ Nomenclature and abbreviations } \\
\hline A & Area $\left[\mathrm{m}^{2}\right]$ \\
\hline AirGasRatio & $\begin{array}{l}\text { Ratio of air and } \\
\text { exhaust gas mass } \\
\text { flows }\end{array}$ \\
\hline $\mathrm{B}$ & Bore $[\mathrm{m}]$ \\
\hline $\mathrm{BDC}$ & Bottom Dead Centre \\
\hline $\mathrm{CA}$ & Closing Angle \\
\hline $\mathrm{Cp}$ & Isobaric heat capacity \\
\hline $\mathrm{c}_{\mathrm{x}}$ & Aerodynamic drag \\
\hline $\mathrm{D}$ & Diameter [m] \\
\hline $\mathrm{F}$ & Force $[\mathrm{N}]$ \\
\hline $\mathrm{f}$ & Friction coefficient \\
\hline fmep & $\begin{array}{l}\text { Friction mean } \\
\text { effective pressure }[\mathrm{Pa}]\end{array}$ \\
\hline $\mathrm{g}$ & $\begin{array}{l}\text { Gravitational } \\
\text { acceleration }\left[\mathrm{m} / \mathrm{s}^{2}\right]\end{array}$ \\
\hline $\mathrm{HE}$ & Heat Exchanger \\
\hline HP & High Pressure \\
\hline ht & Heat transfer \\
\hline ICE & $\begin{array}{l}\text { Internal Combustion } \\
\text { Engine }\end{array}$ \\
\hline $\mathrm{J}$ & $\begin{array}{l}\text { Moment of inertia } \\
{\left[\mathrm{kg} \cdot \mathrm{m}^{2}\right]}\end{array}$ \\
\hline $\mathrm{k}$ & $\begin{array}{l}\text { Thermal conductivity } \\
{[\mathrm{W} /(\mathrm{m} \cdot \mathrm{K})]}\end{array}$ \\
\hline 1 & Length [m] \\
\hline LP & Low Pressure \\
\hline $\mathrm{m}$ & Mass $[\mathrm{kg}]$ \\
\hline$\dot{m}$ & Mass flow $[\mathrm{kg} / \mathrm{s}]$ \\
\hline $\mathrm{n}$ & Number of parts \\
\hline NEDC & $\begin{array}{l}\text { New European } \\
\text { Driving Cycle }\end{array}$ \\
\hline $\mathrm{Nu}$ & Nusselt number \\
\hline $\mathrm{OA}$ & Opening Angle \\
\hline $\mathrm{p}$ & Pressure $[\mathrm{Pa}]$ \\
\hline $\mathrm{P}$ & Power $[\mathrm{W}]$ \\
\hline
\end{tabular}

\begin{tabular}{|l|l|}
\hline $\mathrm{Q}$ & Heat energy $[\mathrm{W}]$ \\
\hline $\mathrm{Re}$ & Reynolds number \\
\hline$\rho$ & Density $\left[\mathrm{kg} / \mathrm{m}^{3}\right]$ \\
\hline $\mathrm{S} 1, \mathrm{~S} 2, \mathrm{~S} 3$ & Pressure sensors \\
\hline $\mathrm{S}_{\mathrm{p}}$ & $\begin{array}{l}\text { Mean piston velocity } \\
{[\mathrm{m} / \mathrm{s}]}\end{array}$ \\
\hline $\mathrm{T}$ & Temperature $[\mathrm{K}]$ \\
\hline $\mathrm{T}$ & Torque $[\mathrm{N} \cdot \mathrm{m}]$ \\
\hline $\mathrm{TDC}$ & Top Dead Centre \\
\hline TR & Transmission \\
\hline WHR & Waste Heat Recovery \\
\hline$\eta$ & Efficiency \\
\hline$\nu$ & $\begin{array}{l}\text { Kinematic viscosity } \\
{[\mathrm{cSt}]}\end{array}$ \\
\hline$\omega$ & $\begin{array}{l}\text { Rotational velocity } \\
{[\text { rpm }]}\end{array}$ \\
\hline
\end{tabular}

34

\begin{tabular}{|l|l|}
\hline \multicolumn{2}{|l|}{ Subscripts } \\
\hline aero & Aerodynamic \\
\hline amb & Ambient conditions \\
\hline bc & Bearing crankshaft \\
\hline br & Bearing connecting rod \\
\hline bv & Bearing camshaft \\
\hline dr & Driving \\
\hline E & Engine \\
\hline exh & Exhaust gasses \\
\hline FD & Final drive \\
\hline GB & Gear box \\
\hline HE & Heat Exchanger \\
\hline HT & Heat transfer \\
\hline in & Inlet \\
\hline out & Outlet \\
\hline p & Piston \\
\hline pump & Pumping loss \\
\hline val & Valve \\
\hline
\end{tabular}




\begin{tabular}{|l|l|}
\hline veh & Vehicle \\
\hline
\end{tabular}

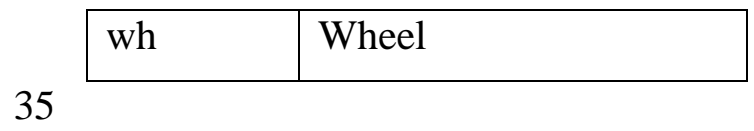

\section{Introduction}

By the current European regulation, car manufacturers must lower the average fleet $\mathrm{CO}_{2}$ emission below $95 \mathrm{~g} / \mathrm{km}$ by the year 2020 [1]. Some car manufacturers would not comply with the regulation if they would keep the same trend of $\mathrm{CO}_{2}$ emission reduction as in the period 2008-2014 [2]. Even the ones whose trend would allow them to reach the objective would probably have to use technologies that are currently not on the market in order to achieve the desired emission. Waste Heat Recovery could be a technology that would provide the reduction of $\mathrm{CO}_{2}$ emission without negatively influencing the emission of other pollutants.

When IC engines operate in the zone of good efficiency, around one third of the energy obtained by fuel combustion is wasted through the heat of the exhaust gasses. There are different known technologies available for Waste Heat Recovery (WHR) to improve the mechanical power of the engine [3] and other technologies for heat management improvements into the engine [4] [5] [6] [7]. Two technologies that have been extensively studied are the Organic Rankine Cycle (ORC) and the Thermoelectric Generator (TEG). While the ORC provides good efficiency [8], it is complex, heavy and requires a lot of space. Generally, research about the ORC focuses on efficiency and viability of the system [9] [10], different proposals for the system layout [11] [12], technologies for the expander machine [13] and the working fluid [14]. On the other hand, TEG systems have a low efficiency, low specific power and their materials are very expensive, [15] but they are simple and robust systems. It is a topic of high interest. Published studies on this topic deal with issues related to the materials and the layout of thermoelectric elements [16] and the viability to recover energy from the exhaust gasses of a car engine [17] [18]. Considering these studies on these two systems, a Brayton cycle could possibly be a compromise solution that could offer relatively good efficiency and simplicity without occupying much space or adding a significant weight into the vehicle. Nevertheless, publications about the application of the Brayton cycle system for WHR in a passenger car are scarce. In general, Brayton cycles are studied to improve the energy recovered from solar power plants. It is possible to find numerous studies about the cycle layout design for closed Brayton cycles working with $\mathrm{CO}_{2}$ in solar plants can be found [19] [20] [21], the interest of regenerative and inverse Brayton cycles [22] [23] and the turbine design for the Brayton cycle of these solar plants [24]. In addition, WHR using Brayton cycles in IC engines for industrial applications, where space requirements and dynamic conditions are less restrictive, has been studied [25]. However, studies about this system applied to IC engines in vehicles are lacking. Nevertheless, because it is a topic of high interest, some authors begin to consider Brayton cycles for WHR in car engines. Banglin et al. [26] studied the viability of this system assisted with a steam generator by using a theoretical model in GT-Power, concluding that it could be a viable system.

Considering this growing interest in WHR issues for car engines using very compact Brayton cycles, the objective of this paper is to estimate the viability of the WHR Brayton cycle by using a very compact layout, in order to minimize the space and weight requirements of the system. To reduce these requirements, a very simple open loop cycle is proposed using only two main elements, first a heat exchanger to take the heat from the exhaust gasses and second, a newer design of a volumetric compression-expansion 
machine, in order to minimize the space requirements of the machine for the compression and expansion processes. This paper represents the continuation of the authors' previous research on Brayton cycle WHR system [27], where it was estimated that the recuperated power could be $1515 \mathrm{~W}$ for the engine working condition that corresponds to car velocity of $120 \mathrm{~km} / \mathrm{h}$.

\section{Model description}

The car that was used in the study was a Ford Mondeo with an Ecoboost 2.0 engine which is a typical European D segment family car. Car engine was a 2 litre turbocharged gasoline engine that at $120 \mathrm{~km} / \mathrm{h}$ produces $22548 \mathrm{~W}$ at $2623 \mathrm{rpm}$. For this paper the same vehicle, engine and operating point were used. It was considered that the model that was used in current study could be further improved in order to obtain a more realistic Brayton cycle model. Some of the conclusions from the first paper will serve as an initial condition for this study. The most important ones are that the same piston machine will be used both as a compressor and expander and that the diameter of the piston will be $120 \mathrm{~mm}$.

The modelled Brayton cycle is an open loop thermodynamic cycle that consists of five main processes: compression, heat addition, expansion, exhaust process and intake process. Regarding the processes of compression and expansion, it was estimated that for both processes alternating piston could be a promising technology to use. Furthermore, similar piston diameter was estimated for both processes. In the present paper, in order to reduce size and weight of the machine, it was considered that one alternating piston could be used for both processes, while compression process would take one piston stroke the expansion process would continue during the next stroke. At the end of expansion the air temperature is higher than ambient air. For the process of heat rejection two more piston strokes were used. These two strokes would be used to expel the hot air from the previous cycle and admit the fresh air for the new cycle. Regarding the process of heat addition, heat is introduced into the cycle through the heat exchanger by a heat exchange process between the air (gas cycle) and the ICE exhaust gasses.

The engine used in this study was tested by modelling the car. The main engine parameters were measured for car velocity of $120 \mathrm{~km} / \mathrm{h}$, as it is a regular speed of the vehicle with a high rate of heat energy into the exhaust line. The most important engine characteristics are presented in [Table 1] while the most relevant engine characteristics for the studied engine operating point are presented in Table 2.

\begin{tabular}{|l|c|}
\hline Characteristic & Value \\
\hline Displacement $\left[\mathrm{cm}^{3}\right]$ & 1999 \\
\hline Maximum Power [kW] & 149 \\
\hline Maximum Torque [Nm] & 300 \\
\hline
\end{tabular}

Table 1. Engine characteristics

\begin{tabular}{|l|c|}
\hline Characteristic & Value \\
\hline Exhaust gas mass flow $[\mathrm{g} / \mathrm{s}]$ & 27.01 \\
\hline Exhaust gas temperature $\left[{ }^{\circ} \mathrm{C}\right]$ & 733 \\
\hline Rotational speed $[\mathrm{rpm}]$ & 2623 \\
\hline Effective power $[\mathrm{W}]$ & 22548 \\
\hline
\end{tabular}


114 From the engine operating point data and assuming $25^{\circ} \mathrm{C}$ as the reference ambient temperature $\left(T_{a m b}\right)$, the available heat power of exhaust gasses $\left(P_{e x h}\right)$ can be estimated as:

$$
P_{\text {exh }}=\dot{m}_{\text {exh }} \cdot C_{\text {pexh }}\left(T_{\text {exh }}-T_{a m b}\right)=19353 \mathrm{~W}
$$

Where $\dot{m}_{e x h}$ is the exhaust gas mass flow, $T_{e x h}$ is the temperature of exhaust gasses and $C_{p e x h}$ is the isobaric mass heat capacity of exhaust gasses. Considering these values, the present Brayton cycle system consists of two main elements: the heat exchanger and the compressor-expander machine. Regarding the first element, heat exchanger model was validated by using experimental measurements on a prototype. For the piston machine, there was no prototype made instead the model uses empirically confirmed relations form the similar technology of reciprocating internal combustion engines. In this study some machine design parameters and dimensions were defined. Valve timing and stroke were used as variables that provide variation of heat exchanger pressure and air to exhaust gas mass flow ratio in order to maximize the recuperated power and to analyse the viability of the cycle. Figure $1 \_$Error! No se encuentra el origen de la referencia. shows the schematic of the cycle and naming convention that was used. Figure shows only the High Pressure (HP) valves while there are two more Low Pressure (LP) valves, that are not shown, that connect the piston machine with the ambient. Figure shows the configuration used in the model. A HP outlet valve that connects the piston machine with the heat exchanger is presented as a reed valve and a HP inlet valve that connects the heat exchanger with the piston machine is a poppet valve.

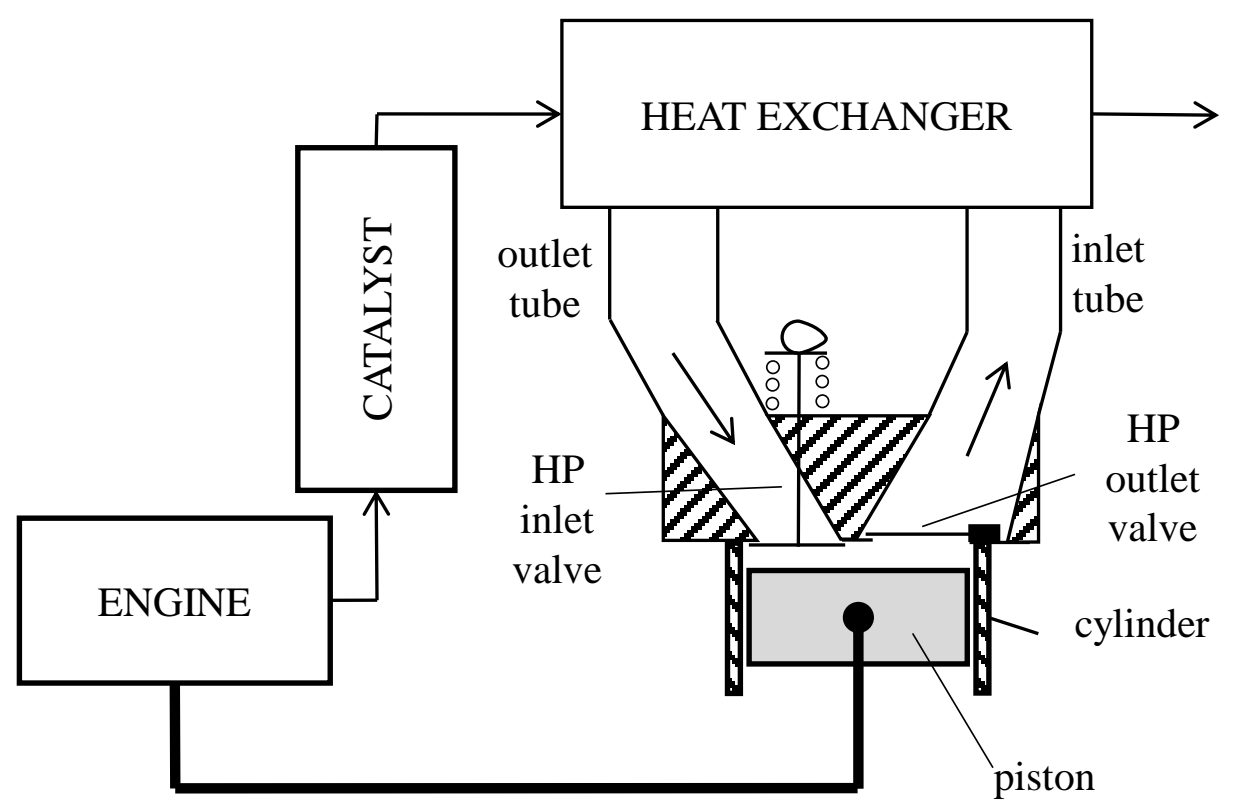


Heat exchanger model was validated by experimental measurements of a prototype. The prototype of the heat exchanger was a gas-gas, cross flow, plate-fin

140 recuperator. Overall dimensions of the heat exchanger were $311 \times 282 \times 103 \mathrm{~mm}$ in order to obtain a compact design minimizing size and weight. Heat exchanger was tested on a steady flow test bench in order to estimate heat exchanger efficiency and pressure drops on air and gas side. The model of heat exchanger was implanted in the WHR recovery system along with the piston machine. To model the behaviour of this element two phenomena have been considered, heat transfer and pressure drop.

\section{Heat transfer}

To determine the heat transfer through the heat exchanger the parameter of heat exchanger efficiency has been used, this parameter is defined as:

$$
\eta_{H E}=\frac{T_{a i r, o u t}-T_{a i r, i n}}{T_{g a s, \text { in }}-T_{a i r, i n}}
$$

Temperatures of air and gas at the inlet were imposed on the test bench along with the mass flows of air and gas. Temperatures of the air and gas at the outlet were measured and heat exchanger efficiency was correlated by using these experimental measurements. Heat exchanger efficiency was measured for various ratios of air and exhaust gas mass flows (AirGasRatio). Figure 2 shows that the relation between heat exchanger efficiency and AirGasRatio was very linear so it was defined in the model as:

$$
\eta_{H E}=-0.2956 \text { AirGasRatio }+1.055
$$

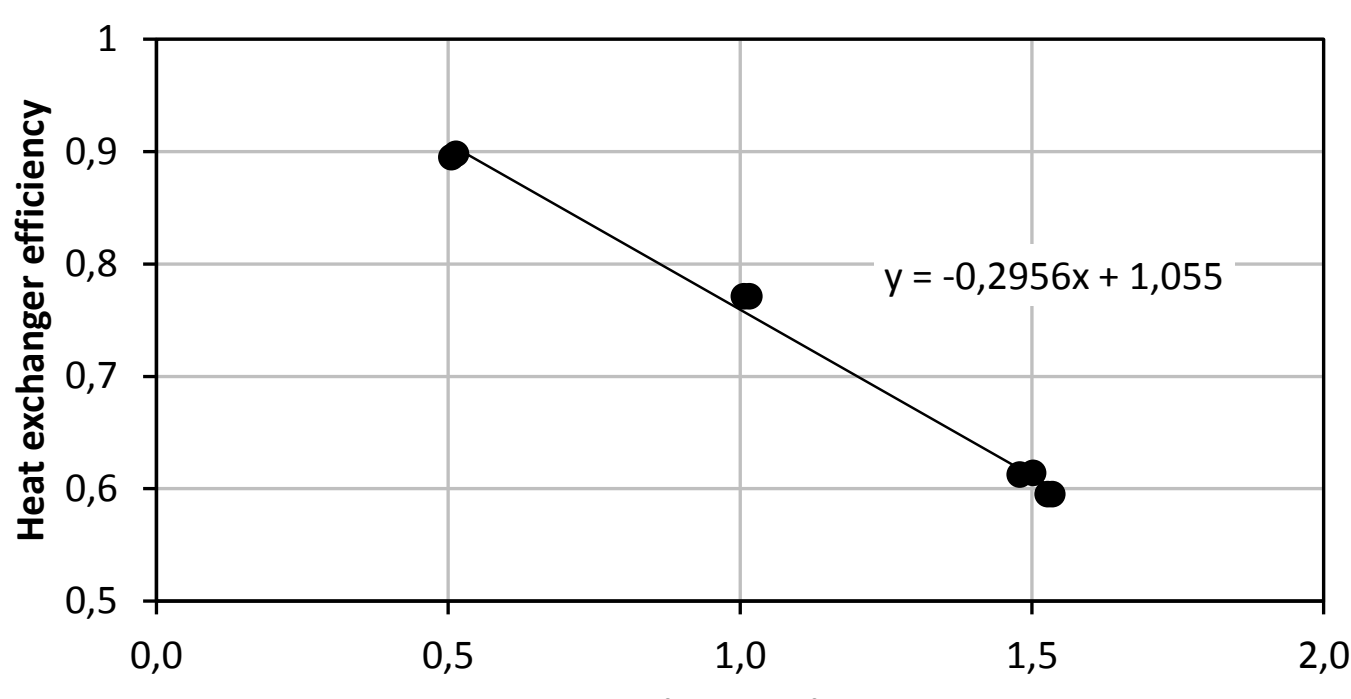

Figure 2. Heat exchanger efficiency as a function of AirGasRatio

160 Pressure drop is the difference in pressure at the heat exchanger inlet and outlet. 161 It represents the resistance of flow through the heat exchanger. Pressures were measured 162 at the heat exchanger inlet and outlet, for both air and gas side, for different mass flows 
and temperatures. Heat exchanger is modelled by using the geometrical dimensions of the heat exchanger and pressure drop estimations [28]. The pressure drops in the air and gas sides were modelled by using separate discharge coefficients for each of the components along the heat exchanger model. The air side of the heat exchanger model was composed of five components: inlet diffuser, 90 degrees inlet bend, heat exchanger core, 90 degrees outlet bend and outlet diffuser. On the other hand, the model of the heat exchanger gas side was composed by a volume as its geometry was simpler. Comparison of measured and modelled pressure drops is represented in Figure 3 for the gas side and Figure 4 for the air side. In these figures horizontal axis represents difference of temperatures $\Delta \mathrm{T}$ at the heat exchanger inlet and outlet. The fit between the measured and modelled pressure drop for the gas side is very good and apart from one point, when relative difference is $11 \%$, for all other points the difference is less than $10 \%$. For the air side, the fit is not very good for small mass flow $(10 \mathrm{~g} / \mathrm{s})$ when relative difference between measured and modelled pressure drop is as high as $50 \%$. For medium $(20 \mathrm{~g} / \mathrm{s})$ and high $(30 \mathrm{~g} / \mathrm{s})$ mass flow rate, that better represent the working conditions when WHR system could be used, the fit is very good and except for two points when it is around 15\% for all other points it is less than 6\%. Model of air side pressure drop was used in the model of Brayton cycle WHR system. Model of gas side pressure drop was used to estimate the internal combustion engine power loss because of additional exhaust back pressure (pumping losses) caused by the placement of heat exchanger in the exhaust line.

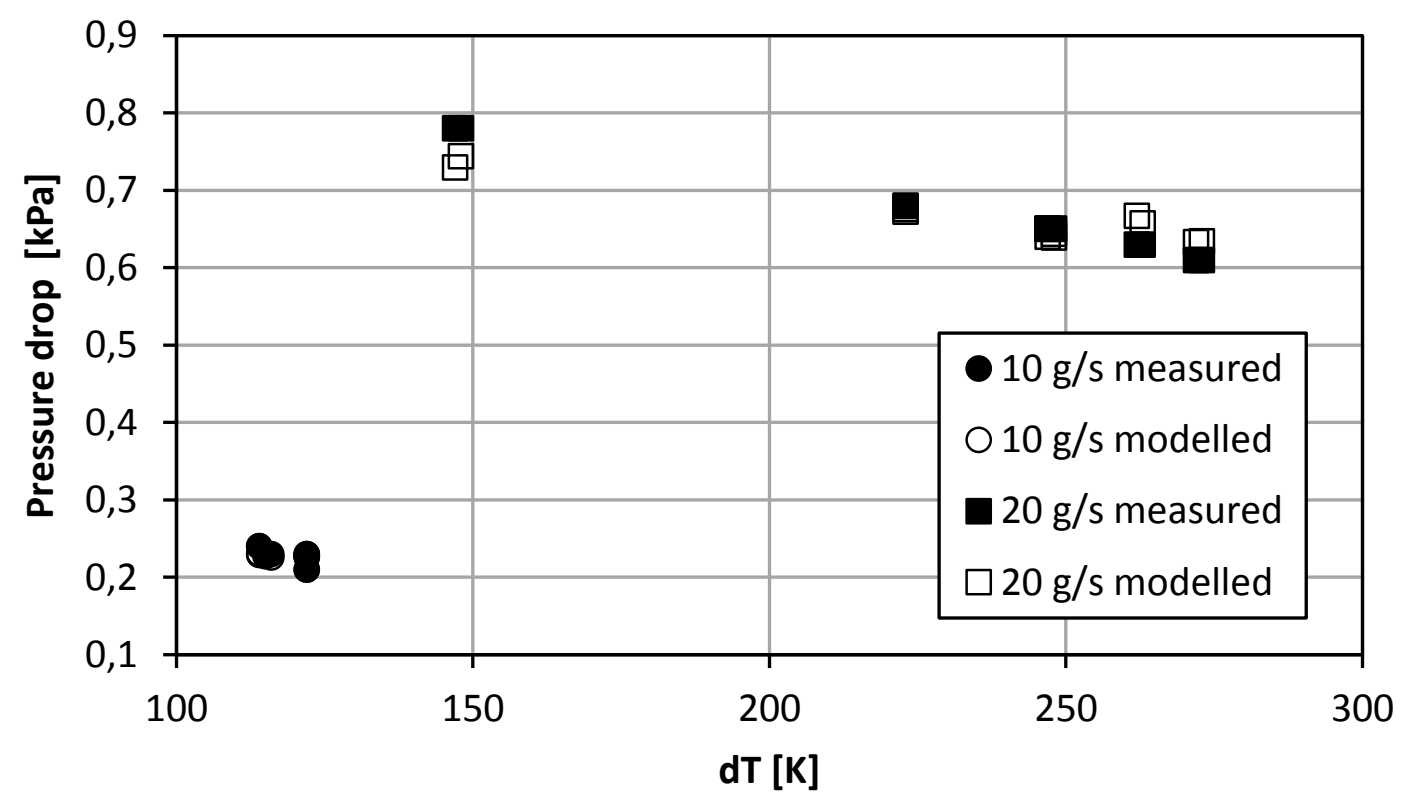

Figure 3. Pressure drop gas side 


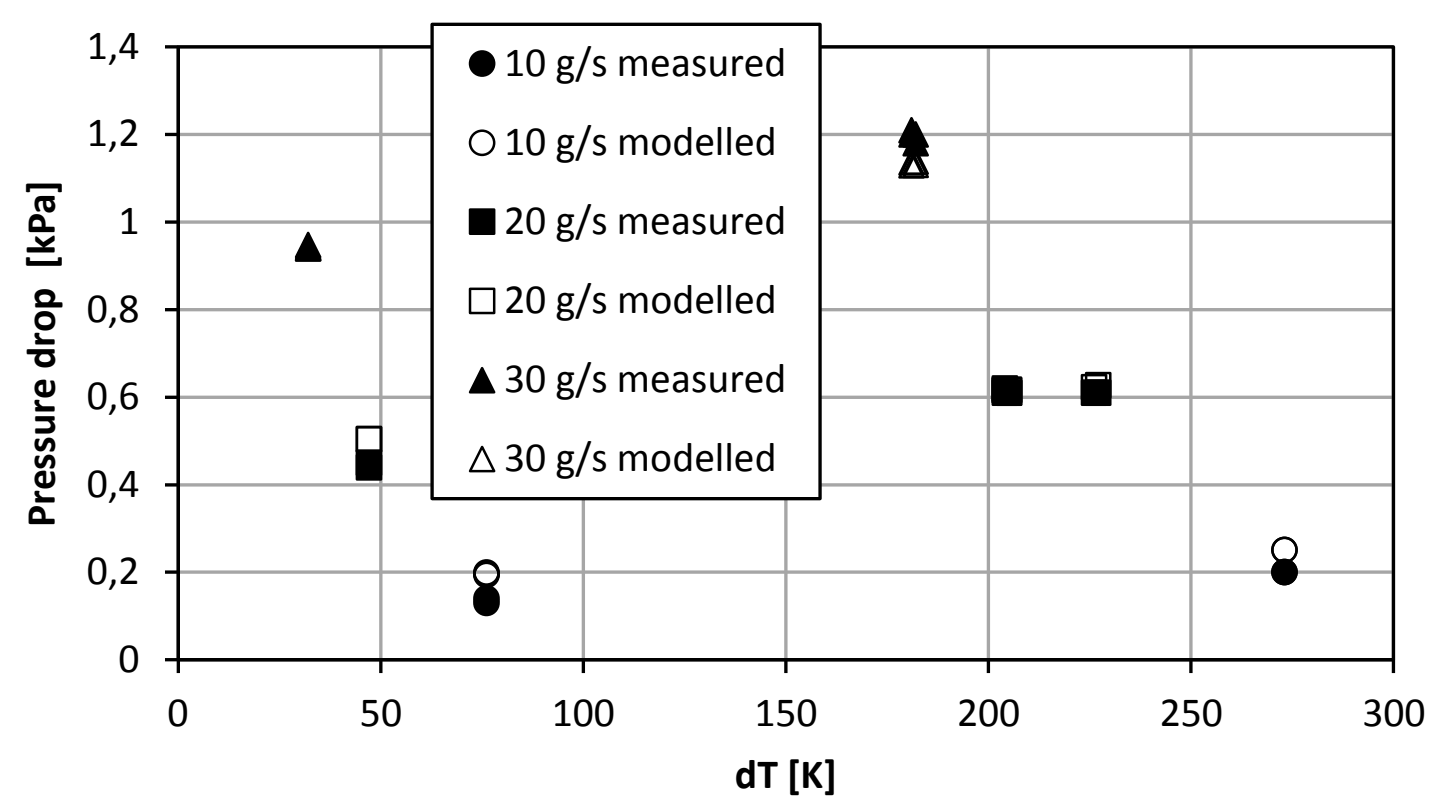

Figure 4. Pressure drop air side

\subsection{Piston machine}

The compression-expansion piston machine is similar to four stroke internal combustion engine cycle but in this case the machine has an external combustion. In ICE the heat is added by the combustion of fuel that is very fast while in the WHR cycle air has to be moved to heat exchanger were it gets warmed by the exhaust gas. The piston machine cycle starts when piston is at the lowest position called Bottom Dead Center (BDC), this position is represented as the 0 crank angle degrees. Piston then starts rising, all the valves are closed and the air that is inside the machine is being compressed. This is the compression stroke that consumes work. In some moment, before reaching the highest position, HP outlet valve opens and air starts moving from the machine to the heat exchanger. Piston reaches the TDC (180 degrees) and starts descending. In some moment, HP inlet valve opens, HP outlet valve closes and air starts moving from the HE to the machine. In some moment during the descending stroke, the HP inlet valve closes and the expansion begins producing a positive work. Piston reaches the BDC (360 degrees) and starts rising. Both LP valves open and air leaves the machine and goes out to the ambient, this is the exhaust stroke. Then, piston reaches the TDC (540 degrees) and starts descending. LP valves remain open and fresh ambient air is admitted for new machine cycle. This is the admission stroke. When this stroke ends, the LP valves close and the cycle ends. As the average pressure during the exhaust process is higher than the average pressure during the intake process this low pressure loop will consume work.

The main differences, comparing to ICE cycle, is that same LP valves could be used to exhaust the air from the previous cycle and admit the fresh air as there are no products of combustion and the natural movement of the air around the machine facilitates the renewal of the air. Although, this temperature is lower than in ICE it is still higher than the temperature of a fresh air. It was assumed in this study that the air is admitted at the ambient temperature. Another difference is that at the end of compression in case of ICE all the valves are closed while for WHR piston machine, the HP valves are open. If some valve is open while piston is at TDC, cylinder pressure would not rise significantly 
even if high compression ratio is used. In this case compression ratio would not be limited 216 by the pressure but by the clearance between the piston and valve or cylinder head. As this clearance could be very small very high compression ratio can be achieved.

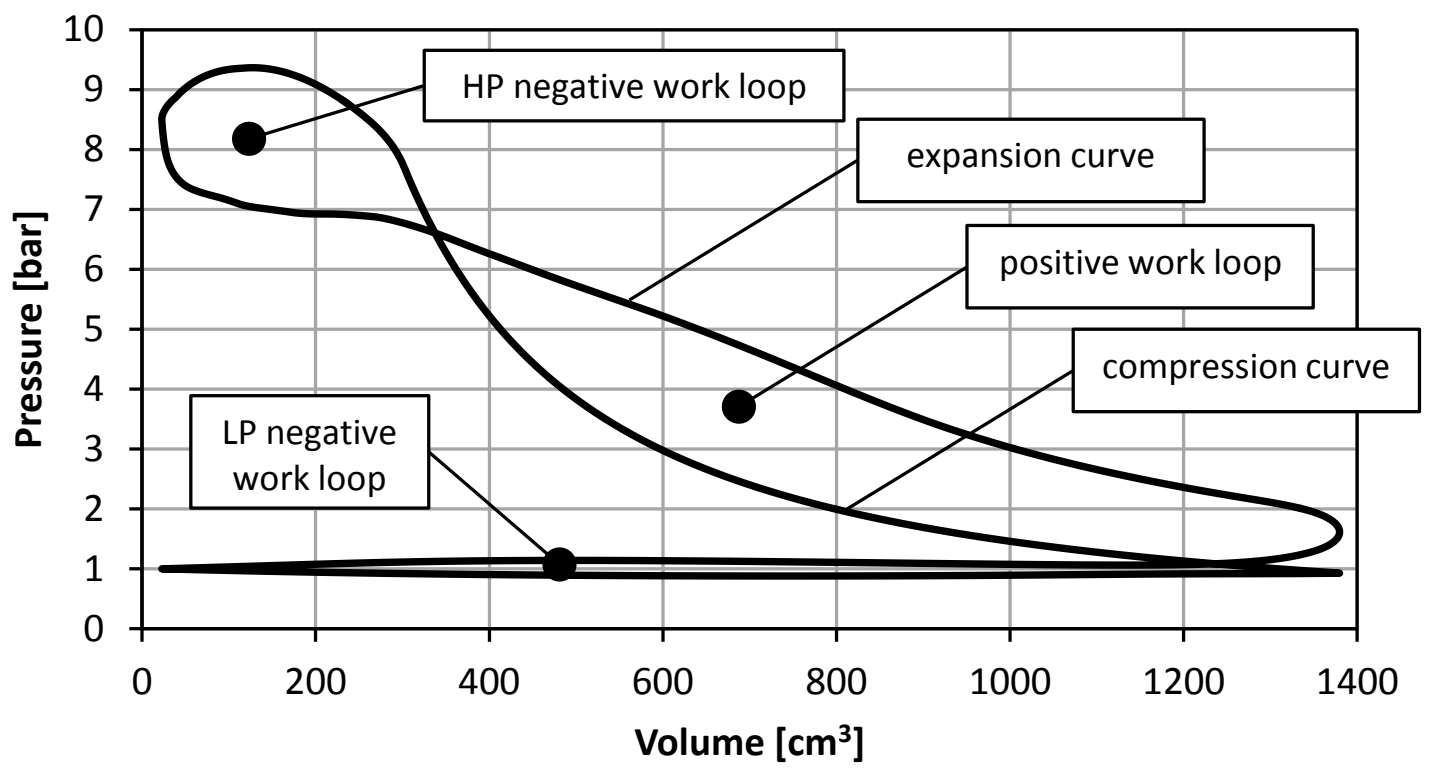

218

Figure 5. Typical Brayton cycle pV diagram

Figure 5 shows the typical pressure-volume diagram of the proposed piston machine. HP negative work represents the pumping work that was consumed by the system to move the air from the piston machine to the HE and back.

To model this element, the machine cycle has been modelled as a $0 \mathrm{D}$ variable volume with two open loops to move the air with negative work (one at high pressure and the other at low pressure) and one closed loop with positive work. Piston diameter was defined in Introduction to be $120 \mathrm{~mm}$ but the stroke was not yet defined. Piston stroke defines the displaced volume and greatly affects the air mass flow through the heat exchanger. Pumping losses of both LP and HP cycle parts also have a big influence. Initially, the value for stroke was taken from the recommendation of bore to stroke ratio for ICE. Heywood [29] suggests stroke to bore ratio in the range of 0.9-1.1 for the passenger car application. The mean value of this range, the value of 1 was decided for stroke to bore ratio. Thereby, stroke was defined to be $120 \mathrm{~mm}$. The model of valves was then made allowing for estimation of pumping losses and air mass flow. Stroke was later used as a variable to analyse the system behaviour. Because the cycle is very similar to ICE cycle, the first type of valves that was studied was the poppet valve actuated by camshaft that is the standard valve kind for ICE.

\section{Poppet valve}

It was decided to use four valves. Two valves would be in charge for low pressure (LP) part and two valves for high pressure (HP) part. It was assumed that valves for the same pressure part have the same size. Valves should be as large as possible to lower pumping losses. Valve size is limited by the minimum clearance between the valve and cylinder and minimum distance between the valves. In the cylinder head, minimum distance between valves was $0.12 \mathrm{Dp}$ as a recommended value for ICE [30]. Where, Dp 
is the piston diameter. Minimum clearance between the valve and cylinder was $2.5 \mathrm{~mm}$ as a typical value for ICE [31]. Other valve dimensions were taken from recommendations [29]. Cam profile for valve opening and closing and coefficients of discharge for valves were taken from [31]. High pressure valves are specific because of their short timing. While low pressure valves have full piston stroke to open and close, duration of high pressure valve is closer to half the piston stroke. Valve lift of high pressure valves had to be proportionally reduced in order to respect the recommended values of valve acceleration, deceleration and avoid high impact between valve and valve seat. The pressure drop and the mass flow through these valves were modelled by using discharge coefficients of similar valves measured in an air test bench and correlating these coefficients with the opening lift of the valves. Considering that higher pumping losses could be expected at HP valves it was believed that it should be beneficial if HP valves are bigger than LP valves.

\begin{tabular}{|c|c|c|c|c|c|c|c|}
\hline & Case 1 & Case 2 & Case 3 & Case 4 & Case 5 & Case 6 & Case 7 \\
\hline $\begin{array}{c}\text { HP diameter } \\
{[\mathrm{mm}]}\end{array}$ & 39 & 40.5 & 42 & 43.5 & 45 & 46.5 & 48 \\
\hline $\begin{array}{c}\text { LP diameter } \\
{[\mathrm{mm}]}\end{array}$ & 39 & 37.5 & 35.8 & 34.5 & 31.7 & 29.8 & 26 \\
\hline
\end{tabular}

Table 3 shows the 7 cases with different valve diameters that were considered in the study in order to optimize them to the processes of compression and expansion. LP valve diameters were the maximum diameter that could fit respecting selected HP diameter and already mentioned limitations.

Reed valve

The used reed valve model consider the reed valve as a rigid flap rotating around one of its edges. Load on the flap was defined by defining the pressure distribution on each side of the valve. Moment of the inertia for the model was calculated knowing the dimensions and density of the material. Reed valve stiffness was modelled as a torsional spring. Torsion coefficient of the spring was a parameter for optimisation in order to fit better the model to the experimental values. The maximal rotation angle is limited by the maximum aperture of the valve's free end. Pressure distribution on each valve side was modelled according to Flecks model [32]. When the valve is closed overall pressure differential is uniform along the petal and it is equal to the difference between upstream and downstream pressure. When the valve starts to open some part of the pressure distribution remains uniform while the other part has a triangular distribution. At very low lift, pressure differential along the petal length follows the overall differential except at the very end. At high lift, the pressure distribution tends to have a more triangular shape. Figure 6 shows a generic pressure distribution along the reed valve. Horizontal (x) axis represents the distance along the petal length (l) while vertical axis represents the pressure defined by $\mathrm{Y}=\Delta \mathrm{p}(\mathrm{x}) / \Delta \mathrm{p}$. Where $\Delta \mathrm{p}$ is the difference of pressures on each side of the reed valve. Fleck estimated that one part of the distribution remains uniform regardless of valve lift. This part was marked as $\mathrm{Y}_{0}$ in Figure 6 . In the present work the value of $\mathrm{Y}_{0}=0.3$ was used as this was the value used by Fleck et al. Figure 6 shows the three load areas marked 1-3. Each of the loads creates a torque that contributes to total torque that makes the petal rotate. When the valve is closed the pressure distribution is uniform and $b$ is equal to zero. When valve starts opening length $b$ starts augmenting from 
zero to the maximum value defined by ration $(b / 1)_{\max }$. The value of $(b / 1)_{\max }=1$ was used because it offered the better fit with the experimental values. In other words, when the valve is fully open $b$ is equal to 1 .

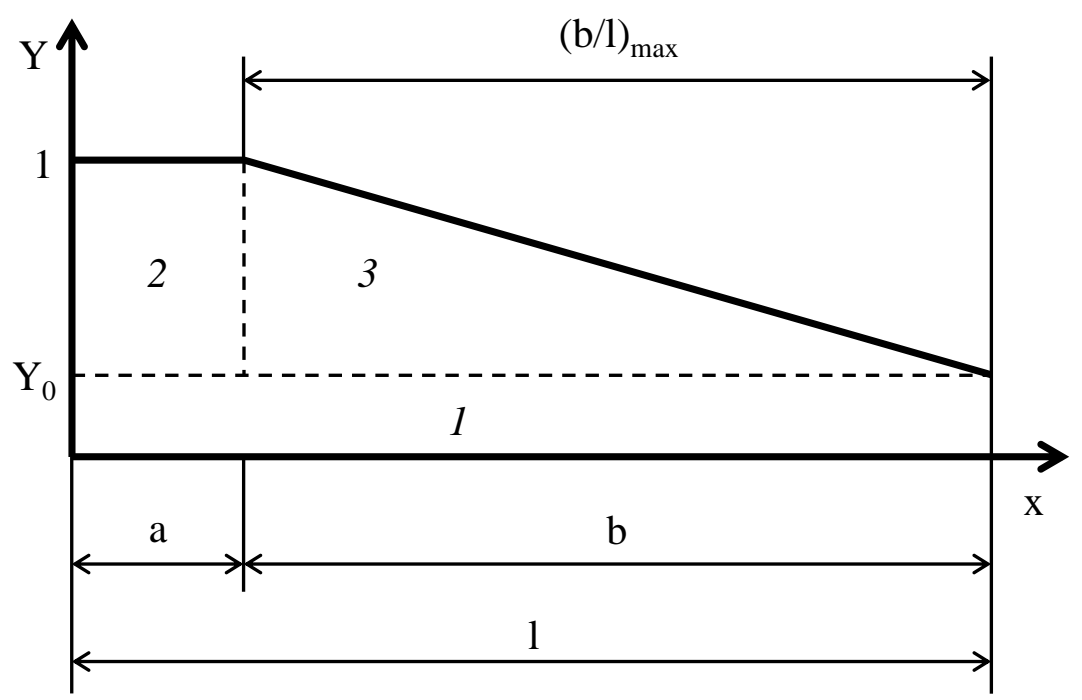

Figure 6. Reed valve pressure distribution

Reed valve model was validated using the data from Blair's experiments [33]. Pressures measured on both sides of the reed valve and petal tip aperture were used to parametrize the model. He also modelled the valve as a cantilever beam and compared his simulation results with measured values. To validate the present thesis's model, same pressures measured by Blair were imposed in the model. Same dimensions, material and mass for reed valve were also used in the model as in the Blair's experiment.

Figure 7 shows the valve lift as a function of time for imposed pressures on each petal side. Red curve represents Blair's measured lift while blue curve represents the results of the Blair's model of cantilever valve with inertia. Black curve represents results of authors' model of rotary flap with inertia. Green curve represents the authors' model of cantilever beam without inertia that was given for a comparison. It can be seen that the valve lift of the rotary flap model used in the present study fits very well with the experimental values of Blair. Rotary flap model does not predict precisely the timing of closing the valve but it does generally predict better the valve lift than Blair's model of cantilever beam. The figure shows that authors' cantilever beam model without inertia does not predict well the valve lift and stresses the importance of using the model with inertia. This proposed model with inertia is the model chosen for the present study. 


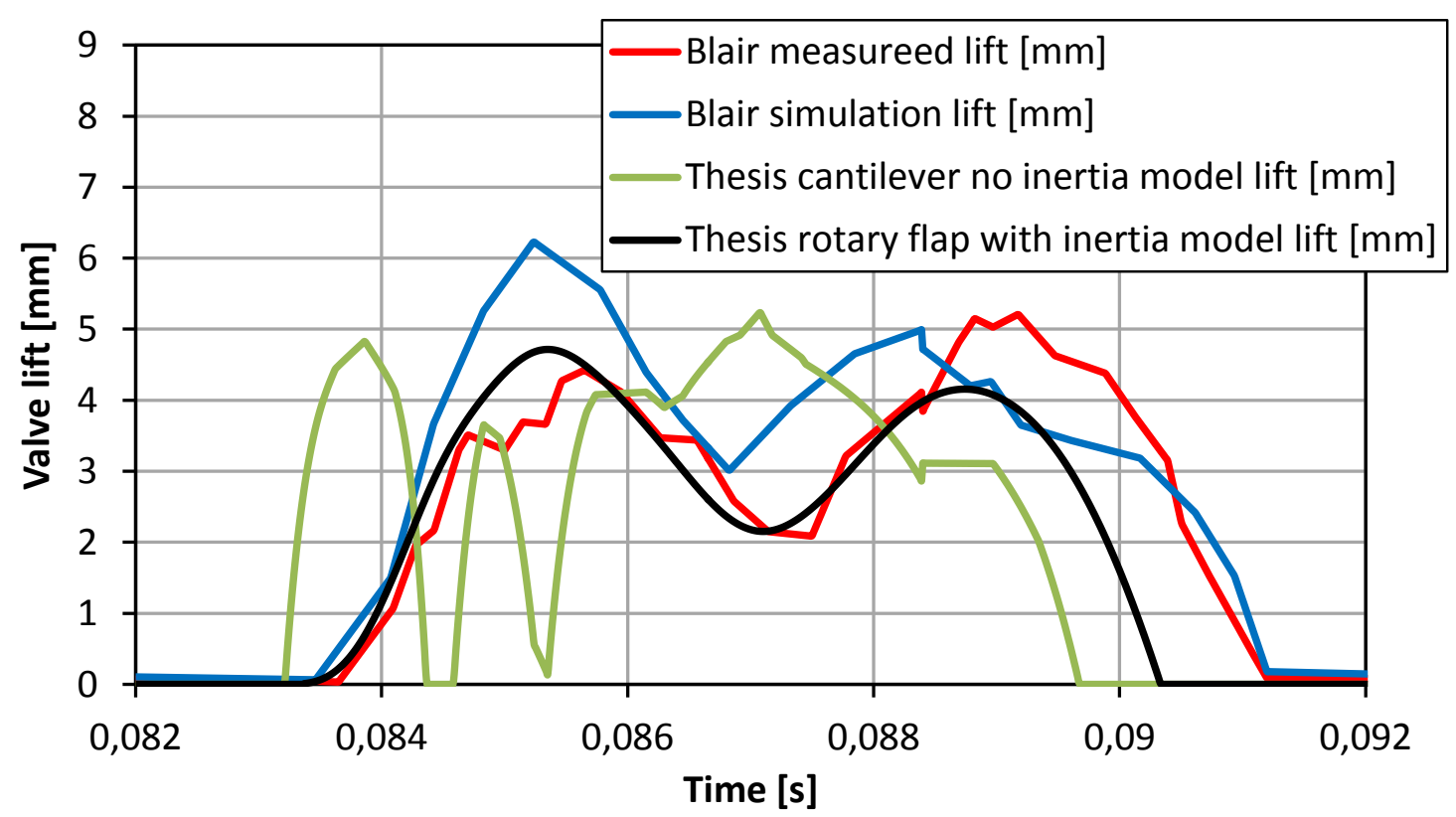

Figure 7. Reed valve lift simulation and measurements

\subsection{Heat transfer model}

Heat transfer from the hot air trapped in the cylinder to colder cylinder walls can be the cause of significant efficiency losses. This heat loss lowers the temperature of the air which comes from the heat exchanger, and consequently the pressure during the expansion, which leads to less work. During the last part of expansion, temperature of the wall gets to be higher than temperature of the air and there is a positive effect of heat transfer but it is to be expected that this part is small. During the compression, pressure and temperature in the cylinder rise. While the temperature of air is less than the cylinder wall temperature, the heat is being transferred from the wall to the air. This warms the air and raises the pressure, which leads to higher work needed for compression. During the last part of compression it is possible that the wall temperature gets lower than air temperature and positive effect of heat transfer occurs but it is reasonable to believe that would the small part. During the expansion process a similar phenomenon occurs but in the opposite direction. In order to take these important effects into account, a heat transfer model was applied. The model of Annand [34] for four stroke ICE was used, so Nusselt number is defined as $N_{u}=0.49 R_{e}^{0.7}$ where Re is the Reynolds number calculated by $R_{e}=\frac{S_{p} D_{p}}{v}$. Where, $\mathrm{S}_{\mathrm{p}}$ is the area for the heat transfer, considered as the sum of piston surface, head surface that is considered to be equal to piston surface and the area of cylinder whose height would depend of crank angle.

In the model, heat is transferred between the air and a single mass (node). This mass represented the sum of piston, cylinder and head equivalent mass. As all tests were for steady conditions, weight of this mass (thermal inertia) is not relevant. It was assumed that there was no heat transfer between this node and the ambient. It means that the global piston machine cycle is considered as an adiabatic process.

\subsection{Mechanical losses}


The model for the mechanical losses is based on the article by Sandoval and Heywood [35]. In this article authors estimate the mechanical losses for different components of gasoline engines. To take into account the difference between the WHR machine and ICE, from the different equations proposed by authors the ones that were obtained from the experiments without the combustion were selected. Mechanical losses greatly depend on part number and their dimensions: cylinder bore, stroke, diameters of bearing journals, lengths of journals, number of bearing, number of valves etc. As a first approximation dimensions of WHR machine were taken from the recommendations for ICE [30] and are presented in Table 4.

\begin{tabular}{|c|c|c|}
\hline Dimension & $\begin{array}{c}\text { Recommended } \\
\text { range }\end{array}$ & Chosen value \\
\hline cylinder bore B & & $120 \mathrm{~mm}$ \\
\hline crankshaft bearing diameter $\mathrm{D}_{\mathrm{bc}}$ & $(0.6-0.7) \mathrm{B}$ & $70 \mathrm{~mm}$ \\
\hline crankshaft bearing length $\mathrm{l}_{\mathrm{bc}}$ & $(0.45-0.6) \mathrm{D}_{\mathrm{bc}}$ & $30 \mathrm{~mm}$ \\
\hline number of crankshaft bearings $\mathrm{n}_{\mathrm{bc}}$ & & 2 \\
\hline diameter of connecting rod bearing $\mathrm{D}_{\mathrm{br}}$ & $(0.55-0.65) \mathrm{B}$ & $65 \mathrm{~mm}$ \\
\hline connecting rod bearing length $\mathrm{l}_{\mathrm{br}}$ & $(0.45-0.6) \mathrm{D}_{\mathrm{br}}$ & $29 \mathrm{~mm}$ \\
\hline number connecting rod bearings $\mathrm{n}_{\mathrm{br}}$ & & 1 \\
\hline number of camshaft bearings $\mathrm{n}_{\mathrm{bv}}$ & & 3 \\
\hline number of poppet valves $\mathrm{n}_{\mathrm{val}}$ & & 2 \\
\hline
\end{tabular}

\subsection{Indirect losses}

Indirect losses are not directly affecting the WHR cycle efficiency. Those losses

losses take into account how application of Brayton cycle WHR system affects the efficiency of the internal combustion engine in the vehicle. As the objective of the WHR is to improve ICE efficiency and lower the fuel consumption of the vehicle those losses must be taken into account. Indirect losses can be divided in two sources: pumping losses because of the additional exhaust backpressure and fuel consumption increase because of the additional rolling friction of the vehicle with the ground due to the weight of Brayton cycle elements.

\section{Exhaust backpressure pumping losses}

Placing the heat exchanger in the exhaust line increases the exhaust back-pressure. This increases the ICE pumping losses because the pistons have to push the exhaust gasses harder to pass them through an additional resistance of heat exchanger. Pressure drop in the heat exchanger increases the negative work of the pumping losses. Equation from [36] was used to estimate the power loss in this process:

$$
P_{p l}=\frac{\dot{m}}{\rho} \Delta p
$$


Density $\rho$ is the mean value of heat exchanger inlet and outlet density. Exhaust gas was considered to have the characteristics of air as an ideal gas. Inlet and outlet densities were calculated as a function of inlet and outlet temperature and pressures. Inlet temperature was defined by the selected ICE operating point. Outlet temperature was estimated from the heat exchanger energy balance.

Additional weight

Implementing the WHR system contributes to additional vehicle weight. With the added weight engine would have to produce more power for the vehicle to travel at the same velocity as it was without this additional weight. Engine power needed for desired vehicle velocity can be calculated by:

$$
P_{E}=\left(F_{d r}+F_{\text {aero }}\right) \frac{1}{\eta_{T R}} v_{v e h}
$$

Where $F_{d r}$ is the driving force, $F_{\text {aero }}$ is the aerodynamic drag force, $\eta_{\mathrm{TR}}$ is transmission efficiency and $v_{\text {veh }}$ is the vehicle velocity.

$$
\text { Driving force is calculated by: } F_{d r}=\left(m_{v e h}+4 \frac{J_{w h}}{R_{w h}^{2}}\right) g f
$$

Where $m_{v e h}$ is the vehicle mass, $J_{w h}$ is the wheel moment of inertia, $g$ is the gravitational acceleration and $f$ is the rolling friction coefficient.

Only the mass of vehicle is changing. Aerodynamic drag force, wheel moment of inertia and wheel radius do not depend on vehicle mass so that the additional engine power can be calculated by:

$$
\Delta P_{E}=\Delta m_{v e h} g f \frac{1}{\eta_{T R}} v_{v e h}
$$

\section{Theoretical studies}

\subsection{Valve timing}

At first, it was considered that all four valves are poppet valves. As there are 4 valves but both LP valves use the same timing that leaves 6 parameters (opening and closing angles) to be optimized.

In order to define a realistic lift, typical lift shapes of IC engine cam valves are used to simulate a realistic lift on these elements. Two strategies were considered for LP valve timing. By the first strategy (labelled as LP 2 strokes), valves open at the start of exhaust stroke and remain open for two strokes. Because the valves are open when piston is at TDC there must be slots (reliefs) in the piston crown for the valves in order to avoid the contact between the piston and valves. These slots increase the dead volume which negatively affects the volumetric efficiency. By the second strategy (labelled as LP 1 stroke), valves open at the start of exhaust stroke and close either fully or partially at the TDC and then open again at start of admission and close at the end of admission. If the valves close only partially there must be again reliefs in the piston crown but this time much smaller because valve lift is less than full lift. For this study, a minimum lift of 2 $\mathrm{mm}$ has been considered on the TDC Closing the valves fully is not desirable because 
high compression ratio causes high pressure rise and high negative work when valves are closed.

400

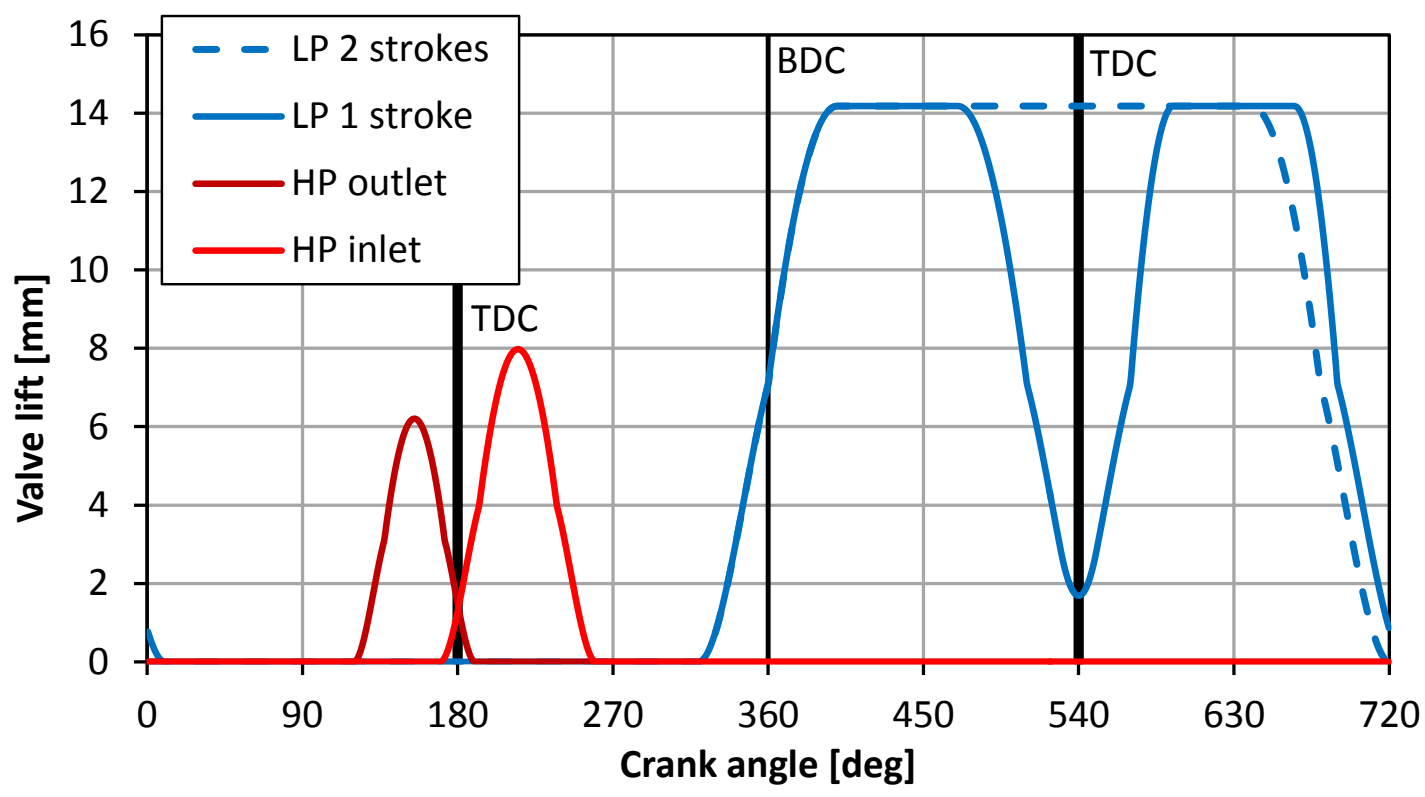

Figure 8. LP valve timing strategies

Figure 8 shows both LP valve strategies. LP 1 stroke strategy represents a better solution than LP 2 stroke because stroke could be shorter for the same mass flow (110 $\mathrm{mm}$ for LP 1 stroke against $130 \mathrm{~mm}$ for LP 2 stroke). As it was already said, the reason for this is the better volumetric efficiency of 1 stroke strategy because of smaller valve reliefs. It can be seen that LP valves open before BDC. Opening the valves before BDC (when pressure in the cylinder is higher than atmosphere pressure) helps expelling the air out and lowers the exhaust pumping losses. By lowering the initial exhaust pumping work, positive work also increases. Valves were opened 40 degrees before BDC. This value was obtained as optimal by simulation varying the opening angle of the LP valves. Earlier valve opening than this lowers the positive work of expansion. Later valve opening than this increases the negative work. It can be seen also that HP valve lifts are much shorter because there is not enough time to fully open the valves. Small HP valve overlap is desirable in order to lower the high pressure rise that would occur as a consequence of high compression ratio if both valves would be closed at TDC. In this case, 20 degrees valve overlap was used. For smaller valve overlap, valves are open very little and the piston cannot suck the air, the pressure in the cylinder decreases rapidly. Higher values of valve overlap were avoided in order to avoid the reflow from the HP inlet valve to HP outlet valve.

This way, there are only 2 parameters left for valve timing optimisation: HP outlet valve open angle (OA) and HP inlet valve close angle (CA). HP outlet valve OA was varied in the range 110-140 crank angle degrees with 10 degrees step. HP inlet valve CA was varied in the range 240-280 crank angle degrees also with 10 degrees step. For the study of maximum recuperated power it was decided to include two more parameters: piston stroke and valve diameters. Piston stroke was varied in the range 70-100 mm with steps of $10 \mathrm{~mm}$. This variation of piston stroke allowed sufficient variation of air mass flow to optimize the machine design. Air mass flow was varied in order to study the effect of AirGasRatio (ratio of air and exhaust gas mass flows) on recuperated power which is 
a variable that will affect the behaviour of the cycle. Different sizes of HP and LP valves were tested in order to estimate the size that would offer better recuperated power. Valve diameters used in the study were defined in the Table 3.

Figure 9 shows the recuperated power as a function of valve diameters. For each point in this figure all other parameters were varied in their respective ranges. The maximum recuperated power of $2157 \mathrm{~W}$ was obtained with HP valve diameter of 43.5 $\mathrm{mm}$ and $\mathrm{LP}$ valve diameter of $34.5 \mathrm{~mm}$.

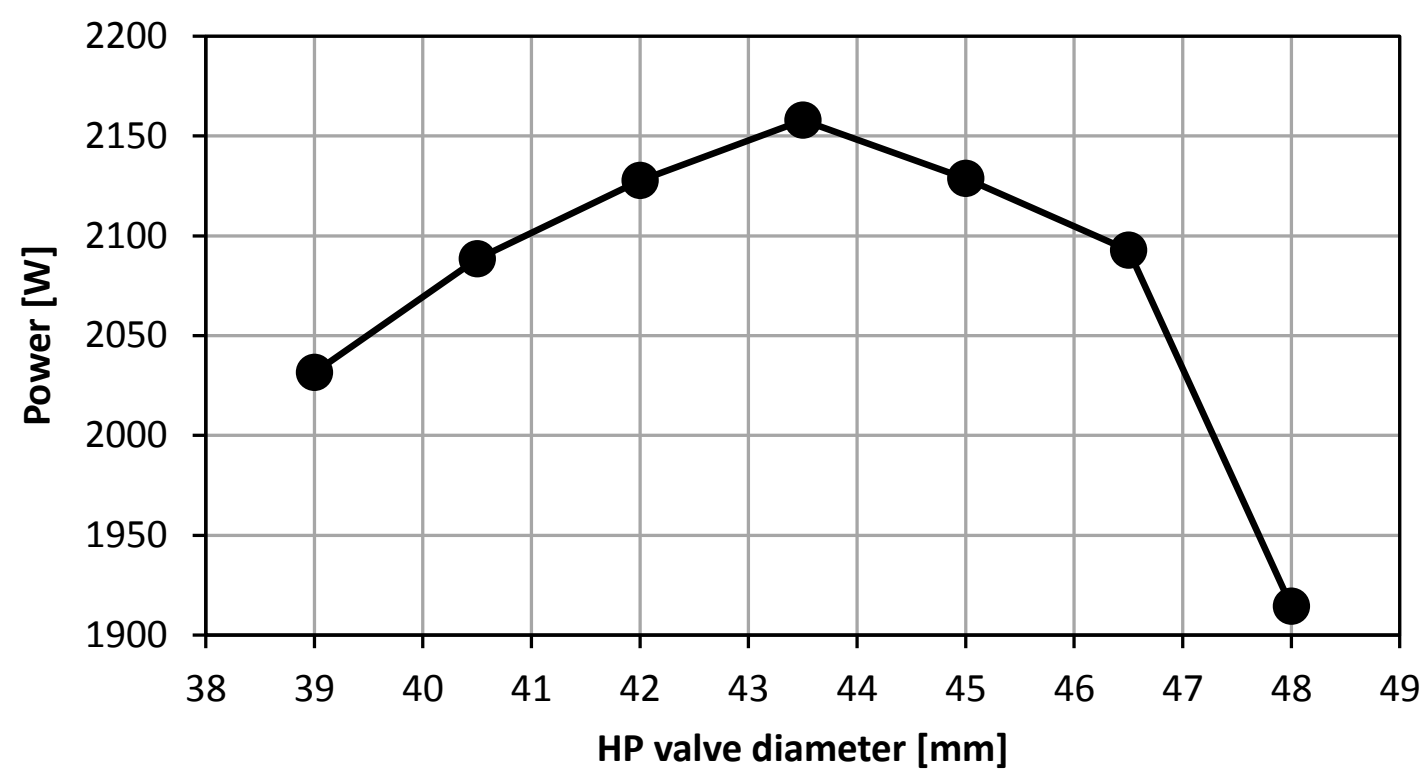

436

Figure 9. Recuperated power as a function of valve diameters

The effects of valve timing and stroke length on recuperated power could better be seen for fixed valve dimensions. Figure 10 shows the recuperated power as a function of piston stroke, HP inlet valve CA and HP outlet valve OA for valve diameters that provided the maximum power (HP valve diameter $43.5 \mathrm{~mm}$, LP valve diameter $34.5 \mathrm{~mm}$ ). For the clarity, the plot shows only the three values of HP outlet valve OA that provided the highest recuperated power. Results of the simulation show that for any HP outlet valve OA the stroke of $90 \mathrm{~mm}$ always provides the highest recuperated power. The optimal HP outlet valve CA changes with HP inlet valve OA. For the HP outlet valve OA of 120 degrees the optimal HP inlet valve CA is 260 degrees, but if the HP outlet valve OA decreases to 110 degrees, the optimal HP inlet valve CA increases to 270 degrees. Maximum recuperated power of $2157 \mathrm{~W}$ was obtained with HP outlet valve OA of 120 degrees, HP inlet valve CA of 260 degrees and stroke length of $90 \mathrm{~mm}$. 


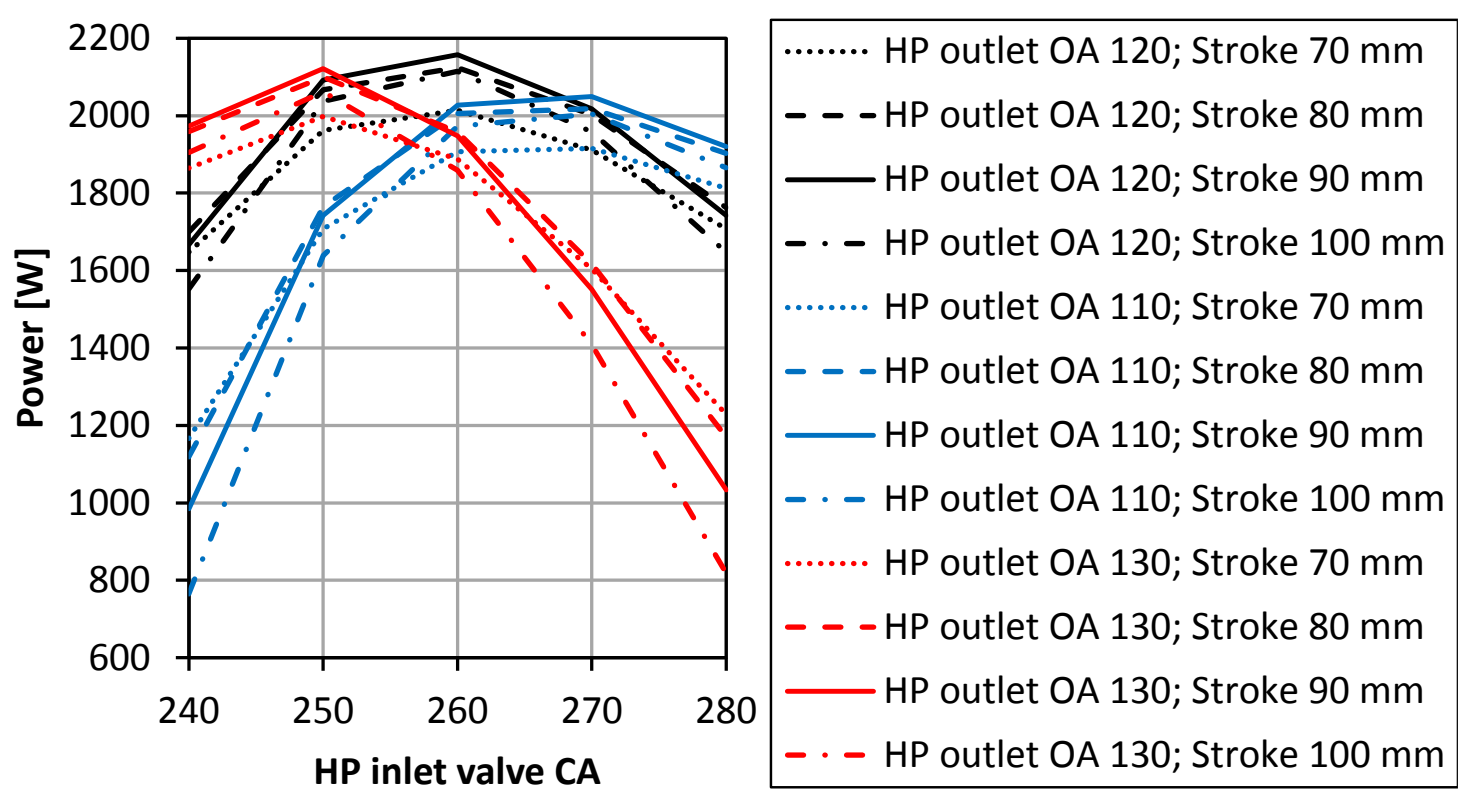

Figure 10. Recuperated power as function of stroke length, HP inlet valve CA and HP outlet valve OA

For this optimal point with a fixed HP outlet valve OA of 120 degrees and a stroke of $90 \mathrm{~mm}$, changing the HP inlet valve CA has a main effect on recuperated power and pressure in the heat exchanger with the secondary effect on air mass flow. This can be seen on Figure 11. HE pressure from the figure represents cycle mean value of the pressure in the heat exchanger. If the HP inlet valve closes later, pressure in the heat exchanger will be lower and air mass flow higher, producing an optimal value that results in highest recuperated power. Recuperated power is highest for HP inlet valve CA of 260 degrees and stroke of $90 \mathrm{~mm}$ when HE pressure is 9.14 bar and air gas ratio is a 0.8 approximately. 


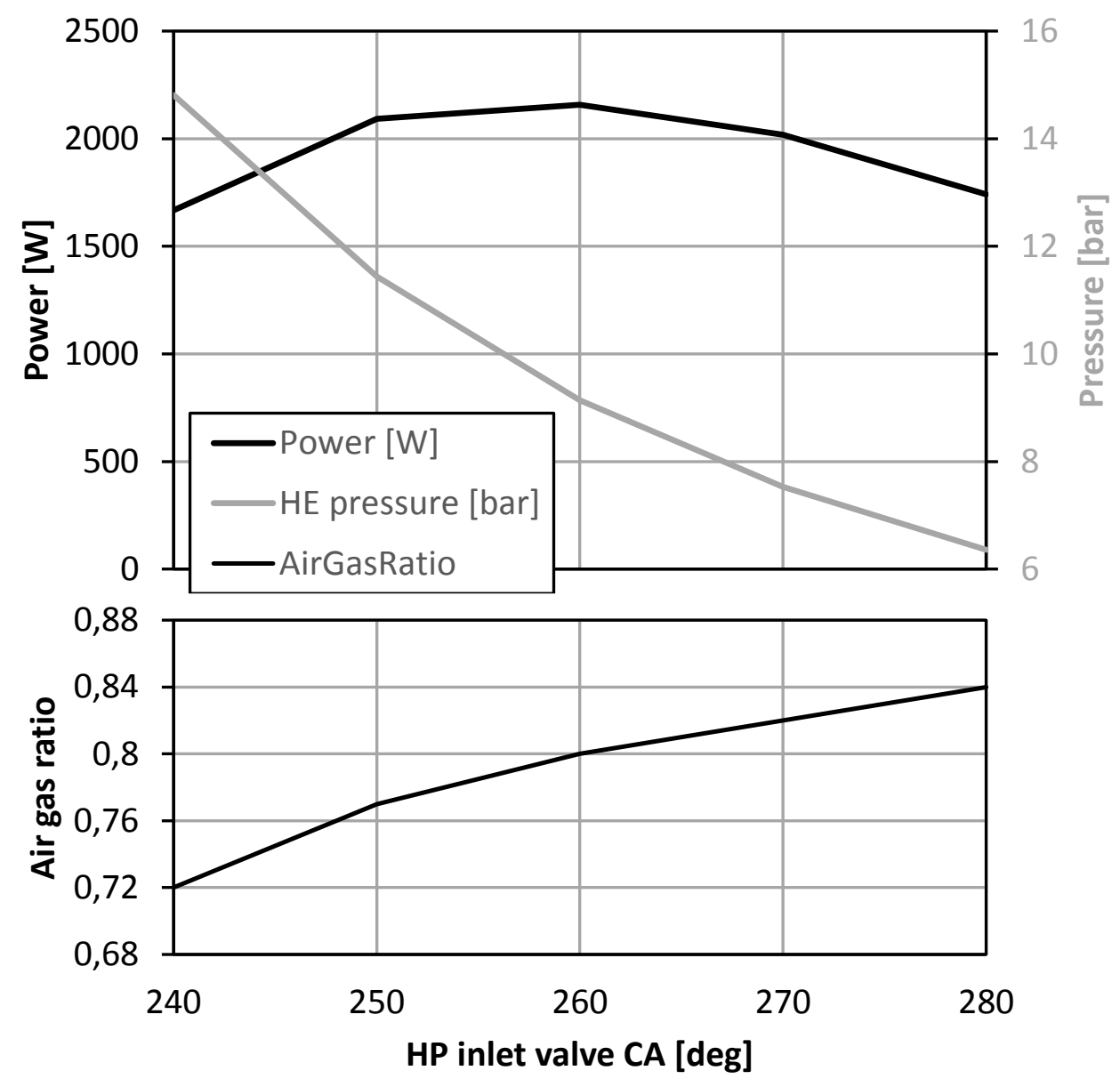

462

463

464

465

466

467

468

469

470

471

472

473

474

475

476

477

478

479

480

481

482

Figure 11. Effect of HP inlet valve CA on pressure in the HE, AirGasRatio and power; stroke $90 \mathrm{~mm}$; HP inlet valve OA 120 degrees

Figure 12 shows the comparison of pressure-volume diagrams for the three cases of HP valve timing. These cases are the points of maximum power for each HP outlet valve OA value from Figure 10. The curves from Figure 12 were named in the following style HP outlet valve OA-HP inlet valve CA-Stroke followed by the recuperated power for that valve timing. For example, the label " $120-260-90 \mathrm{P}=2157 \mathrm{~W}$ " represents the case with HP outlet valve OA of 120 degrees, HP inlet valve CA of 260 degrees and stroke of $90 \mathrm{~mm}$. Highest recuperated power was obtained in this case with a HP inlet valve OA of 120 degrees as it was explained before. Earlier HP outlet valve opening results in the decrease of both HE pressure and cylinder peak pressure. While the difference in power between 120 and $110 \mathrm{HP}$ inlet valve OA is small $109 \mathrm{~W}$, the difference in HE pressure is more significant as the pressure decreases from 9.14 bar to 7.55 bar.

The HP negative work area from the Figure 12 is significantly big. For the case when the recuperated power was maximal (2157 W), HP pumping losses consumed 1220 $\mathrm{W}$ while the positive work generated $3517 \mathrm{~W}$. HP pumping loss is very high and it should be further analysed how to reduce it. The reason for this big loss is that the big quantity of air must be moved from the cylinder to the heat exchanger in a short time period. This creates the high instantaneous mass flow rate that causes the high pressure drop in the HP outlet valve and HP inlet valve. 
While power losses of HP open loop are significant, the power losses of LP open loop are not significant, $140 \mathrm{~W}$ in the case of maximal recuperated power. The long time period to move the air during the low pressure loop compared with the high pressure one produces that significant reduction on power loss.

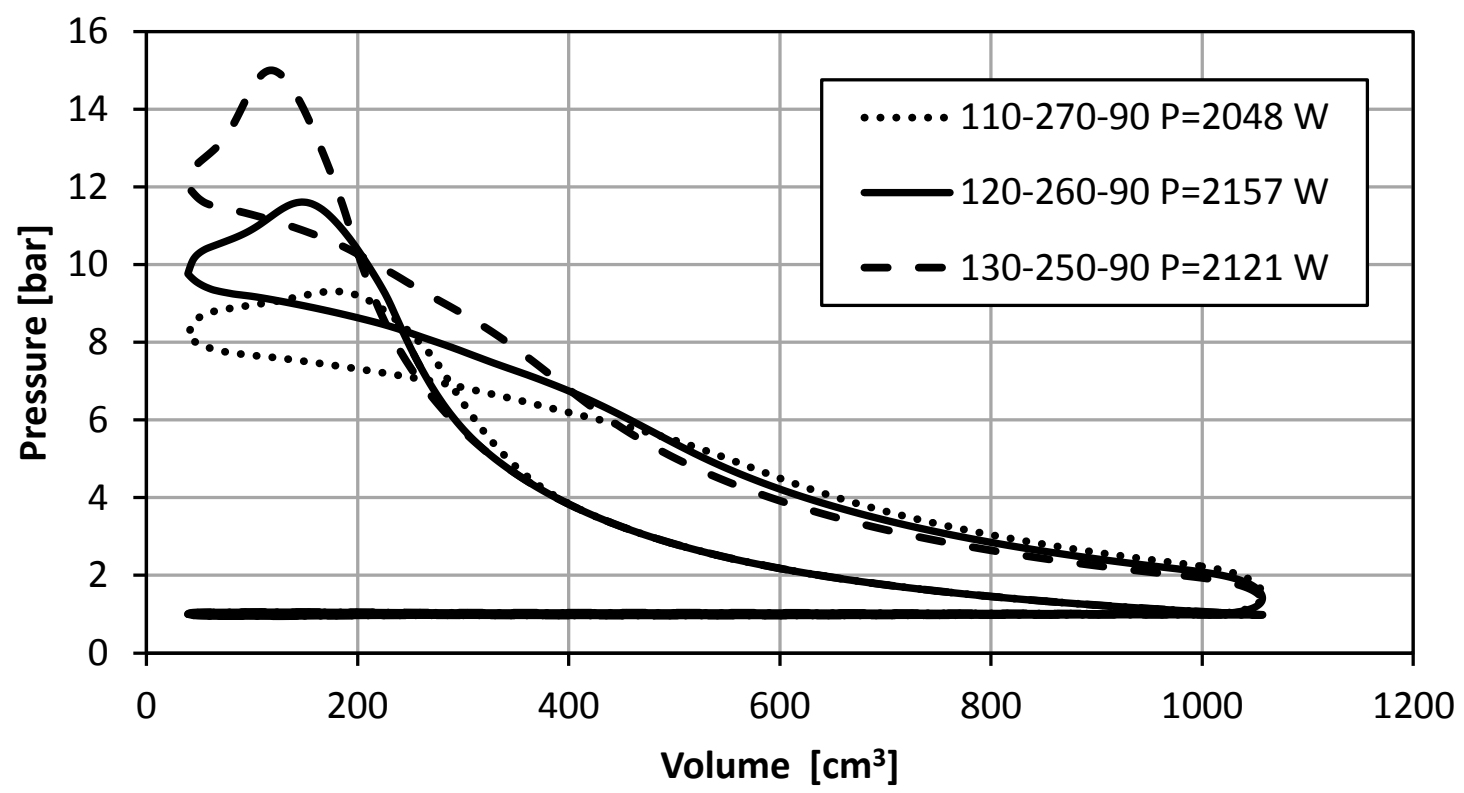

487

488

489

490

491

492

493

494

495

496

497

498

499

500

501

502

503

504

505

506

507

508

509

Figure 12. pV diagram comparison for different HP valve timing

In order to reduce the HP loop negative work and to increase the adaptability of the system, the HP outlet poppet valve has been replaced with a reed valve in the next study. A reed valve model was used to substitute the poppet HP outlet valve model. Two reed petals were placed in the place of substituted poppet valve. The distance between the reed valve and other valves was the same as it was for all poppet valves, when recommendations were used. Figure 13 shows the dimensions and placement of the reed valves in the cylinder head. It was decided to use two reed valves in order to use the entire surface previously occupied by the poppet valve. Timing of the LP valves and HP inlet valve OA were kept the same as for poppet valve. As reed valve opening and closing is automatic and related with the reed valve pressure difference that leaves only 1 parameter (the HP inlet CA) for valve timing optimisation. This parameter was varied in the range 240-280 degrees with the 10 degrees step. Piston stroke was used as a second variable to include the effect of ratio of air and gas mass flows (AirGasRatio). Stroke was varied in the range of $70-100 \mathrm{~mm}$ with the $10 \mathrm{~mm}$ step. Results are presented in Figure 14. The maximum recuperated power was $2386 \mathrm{~W}$ for HP inlet valve CA 250 degrees and a piston stroke of $90 \mathrm{~mm}$ that corresponds to an AirGasRatio of 0.77 . For the case when the recuperated power was maximal $(2386 \mathrm{~W})$, positive work generated $3560 \mathrm{~W}$ while HP pumping losses consumed $1032 \mathrm{~W}$ and LP pumping losses consumed $142 \mathrm{~W}$. HP pumping losses are significant as they consume $28.99 \%$ of the energy generated by positive work loop $(3560 \mathrm{~W})$. The maximum recuperated power for the reed valve model was higher than the one that was obtained with HP outlet poppet valve $(2157 \mathrm{~W})$. 


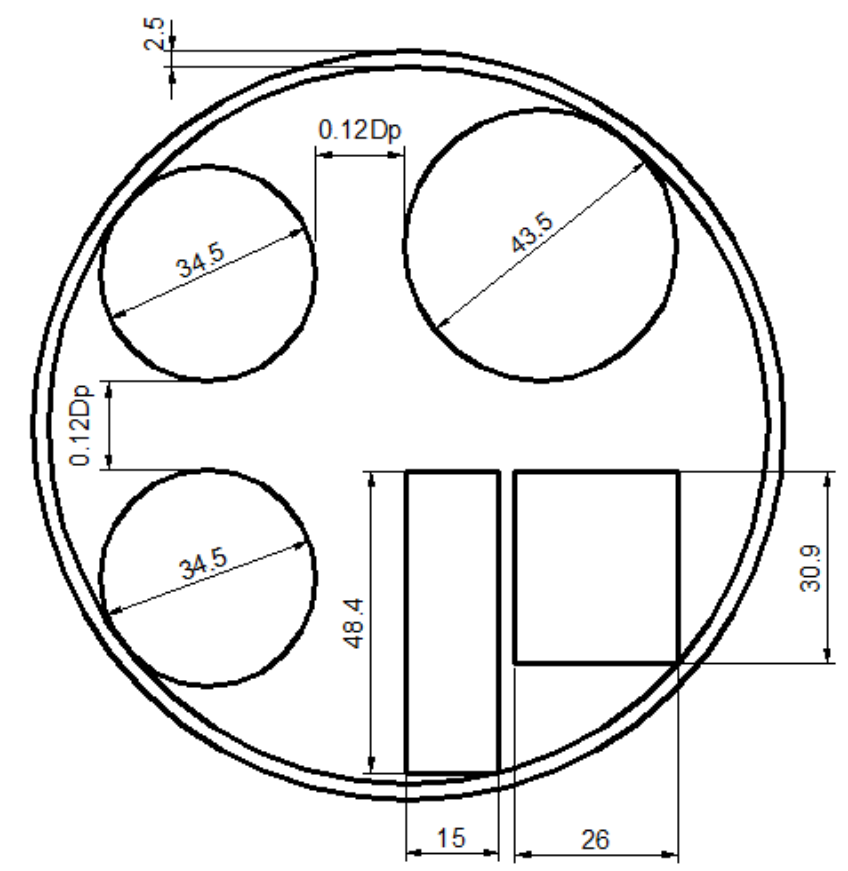

510

511

Figure 13. Placement of reed valves

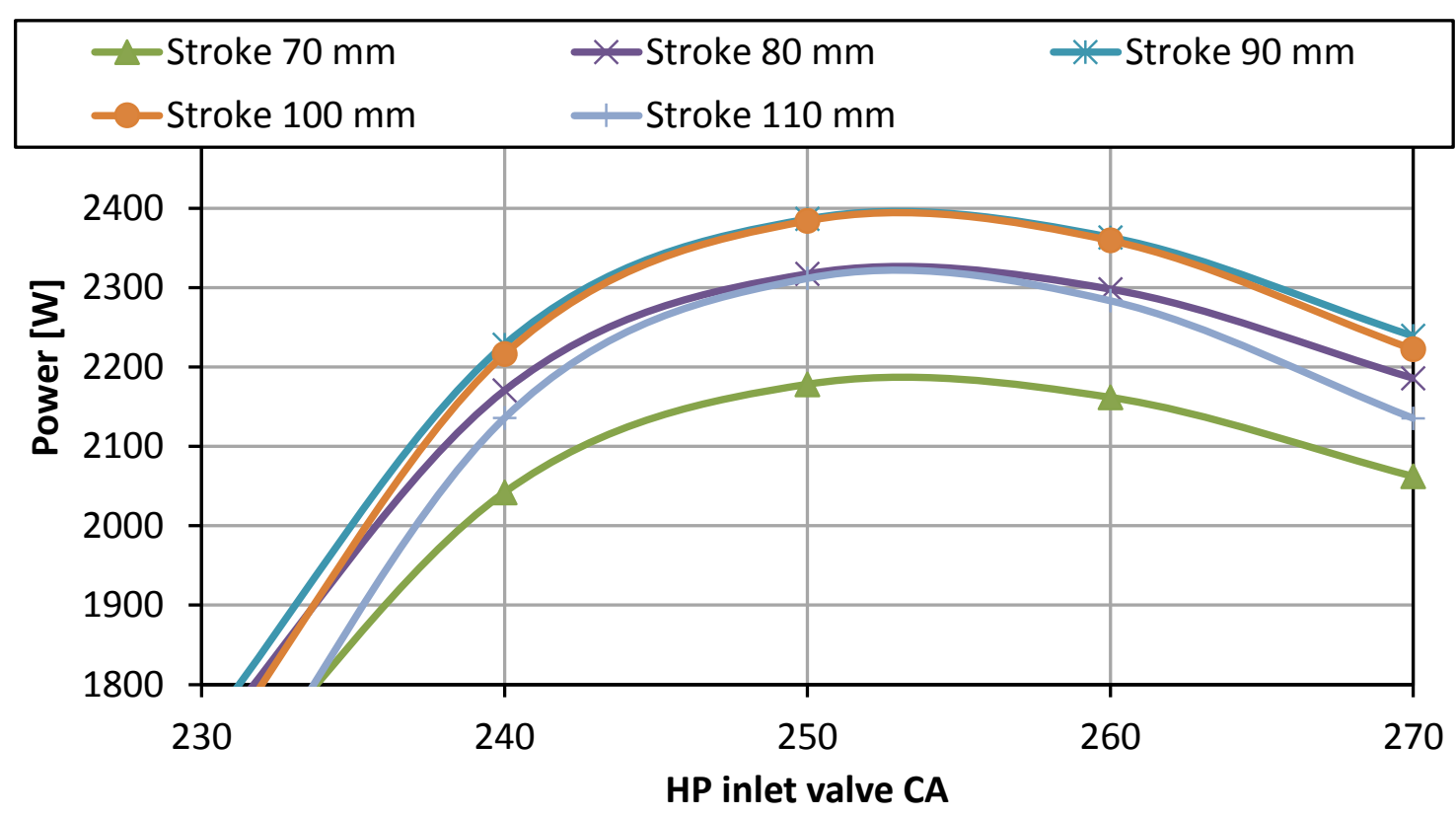

Figure 14. Recuperated power as a function of HP inlet valve CA and stroke

Figure 15 shows the comparison of $\mathrm{pV}$ diagrams for the two cases of HP outlet valve as a reed valve and as a poppet valve. The values of HP inlet valve timing and piston stroke that provided best recuperated power were different for each valve type. Curve named "reed" represents the $\mathrm{pV}$ diagram of the reed valve model for the values of HP inlet valve CA of 250 degrees and stroke of $90 \mathrm{~mm}$ that provided the maximum recuperated power. Likewise, the curve "poppet" refers to $\mathrm{pV}$ diagram of the poppet valve for HP inlet valve CA 260 degrees and stroke of $80 \mathrm{~mm}$ that provided the maximum recuperated power. Because of earlier HP inlet valve closing the pressure of the reed valve is higher and because of the longer stroke the volume is also higher. This makes it difficult 
to compare directly two valve types in the $\mathrm{pV}$ diagram. The curve named "reed comparison" was added in order to compare reed and poppet valve in similar conditions. For this curve the same HP inlet valve timing and stroke was used as for poppet valve. Clearly, the HP negative work of the reed valve is less than the poppet valve.

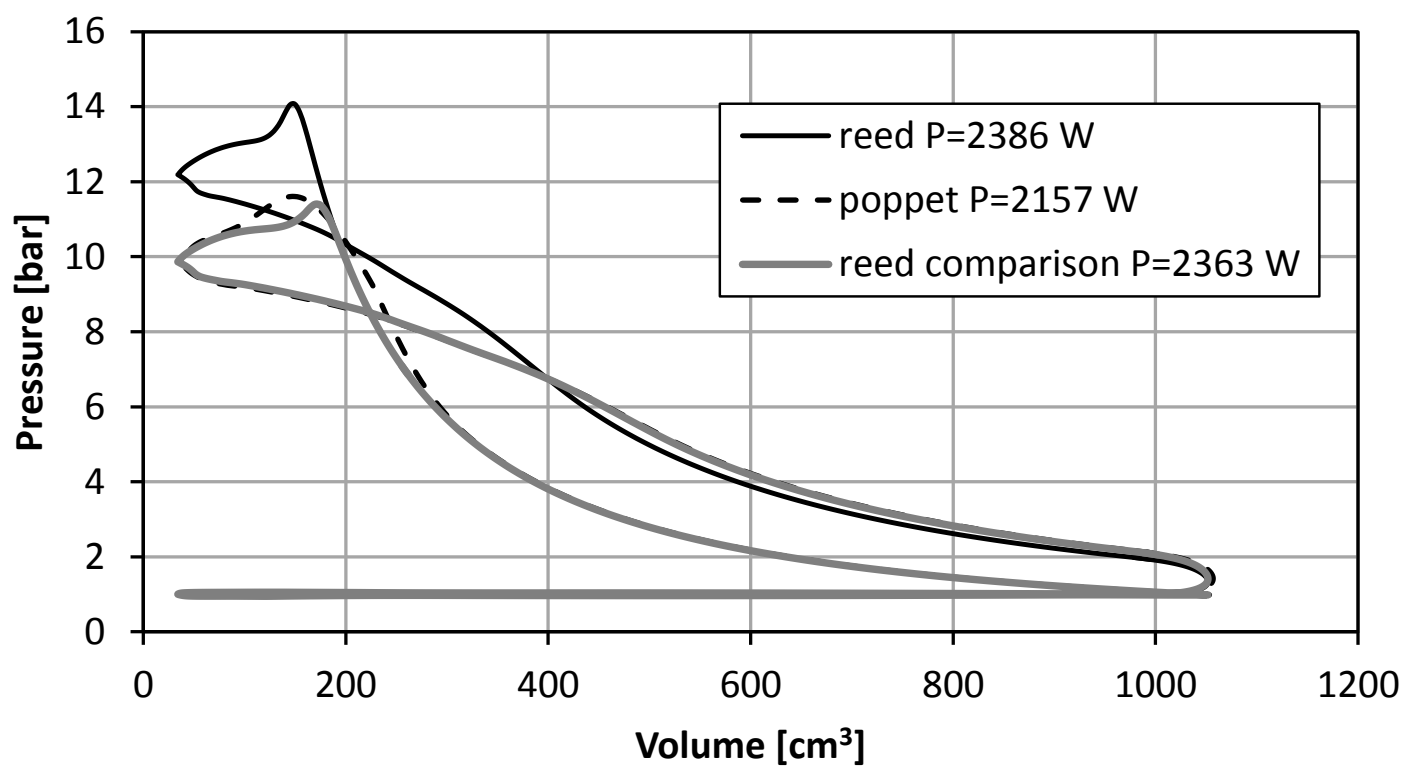

Figure 15. Reed valve pV diagram

\subsection{Heat transfer}

In order to improve the machine model, the heat transfer model described in previous point was applied to the $0 \mathrm{D}$ compression-expansion machine model where reed valve was used as a HP outlet valve and poppet valve as HP inlet valve. As in previous studies, variables were piston stroke and HP inlet valve closing angle (CA). Piston stroke was varied in the range $70-110 \mathrm{~mm}$ and HP inlet valve CA in the range 230-270 degrees. Figure 16 shows the results of recuperated power with the heat transfer model included. A maximum recuperated power of $1662 \mathrm{~W}$ was obtained with HP inlet valve CA of 260 degrees and piston stroke of $80 \mathrm{~mm}$ that provided the AirGasRatio of 0.68. Maximum recuperated power was $724 \mathrm{~W}$ lower than it was for the model without the heat transfer $(2386 \mathrm{~W})$. This power represents $20.34 \%$ of the energy generated by positive work loop for the reference model ( $3560 \mathrm{~W}$ for the model with reed valve and without heat transfer). Due to this effect of heat transfer during the compression and expansion strokes, AirGasRatio that provided the maximum recuperated power was lower than for the model without the heat transfer. Consequently, the piston stroke that provided the maximum power was $10 \mathrm{~mm}$ shorter. 


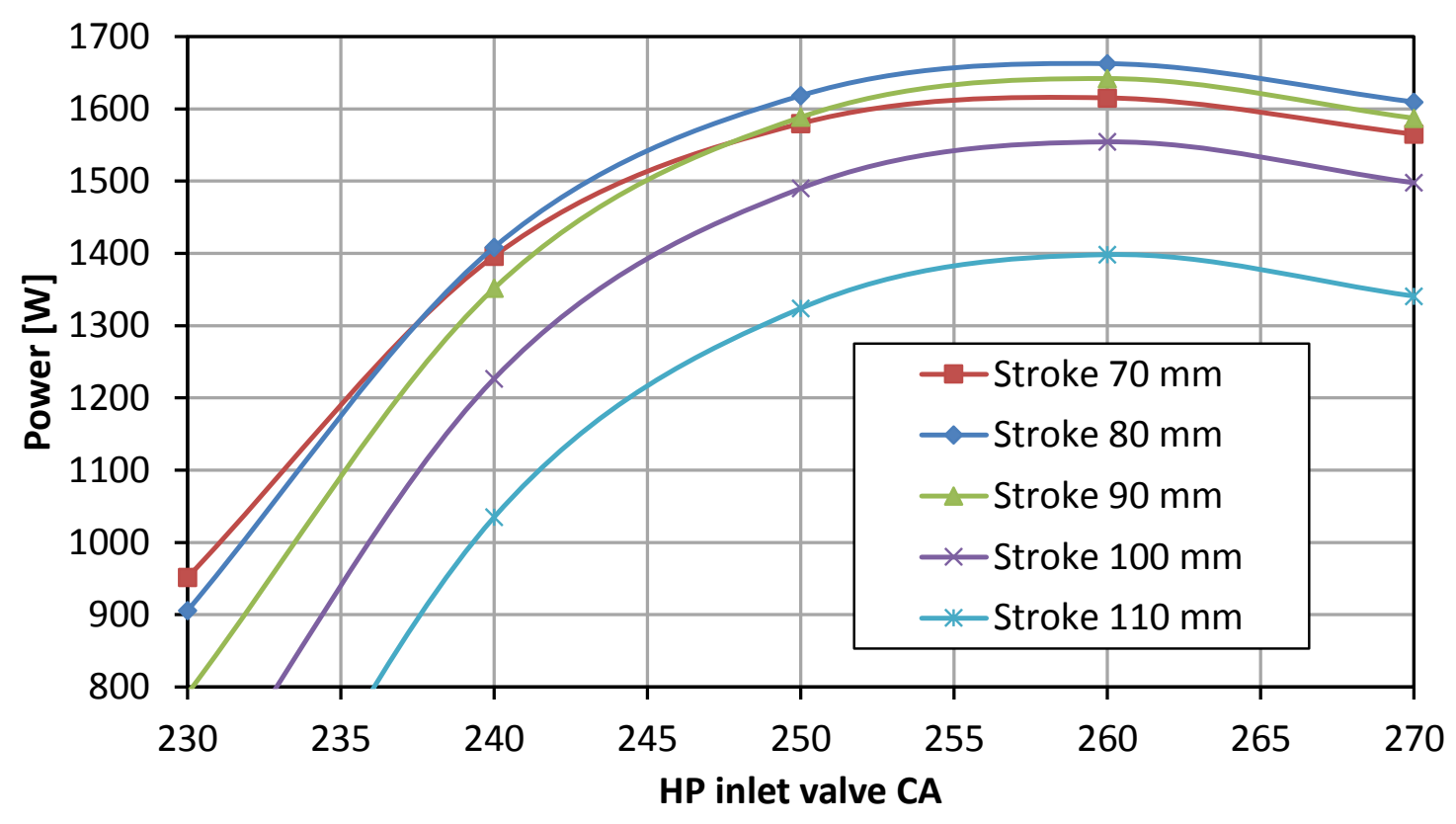

Figure 16. Recuperated power with the heat transfer model

Pressure-volume diagram of the configuration that gave the maximum power is represented in Figure 17 (plot "with heat transfer") along with the same plot for the cycle without the heat transfer. Again, the areas of pressure-volume diagrams cannot be easily compared if HP inlet valve CA and stroke are not the same for both plots. For that reason additional plot is added for the model without the heat transfer. For this plot the same parameters were used that provided the maximum recuperated power for the model with heat transfer (HP inlet valve CA 260 degrees, stroke $80 \mathrm{~mm}$ ). This plot is called "without heat transfer comparison". For this curve, HP inlet valve CA and stroke were not the ones that gave the highest recuperated power. The plot of the model without the heat transfer that gave the maximum recuperated power $(2386 \mathrm{~W})$ is called "without heat transfer". The main difference between the two cycles is that, with the heat transfer, the positive work area is narrower. Compression stroke presents higher pressure values because heat transfer from the warm cylinder wall rises the temperature and the pressure of the air. On the other hand, expansion stroke presents lower pressure values because heat is transferred from the air to the cylinder wall which decreases the air temperature and pressure. These heat transfers decrease significantly the cycle power. 


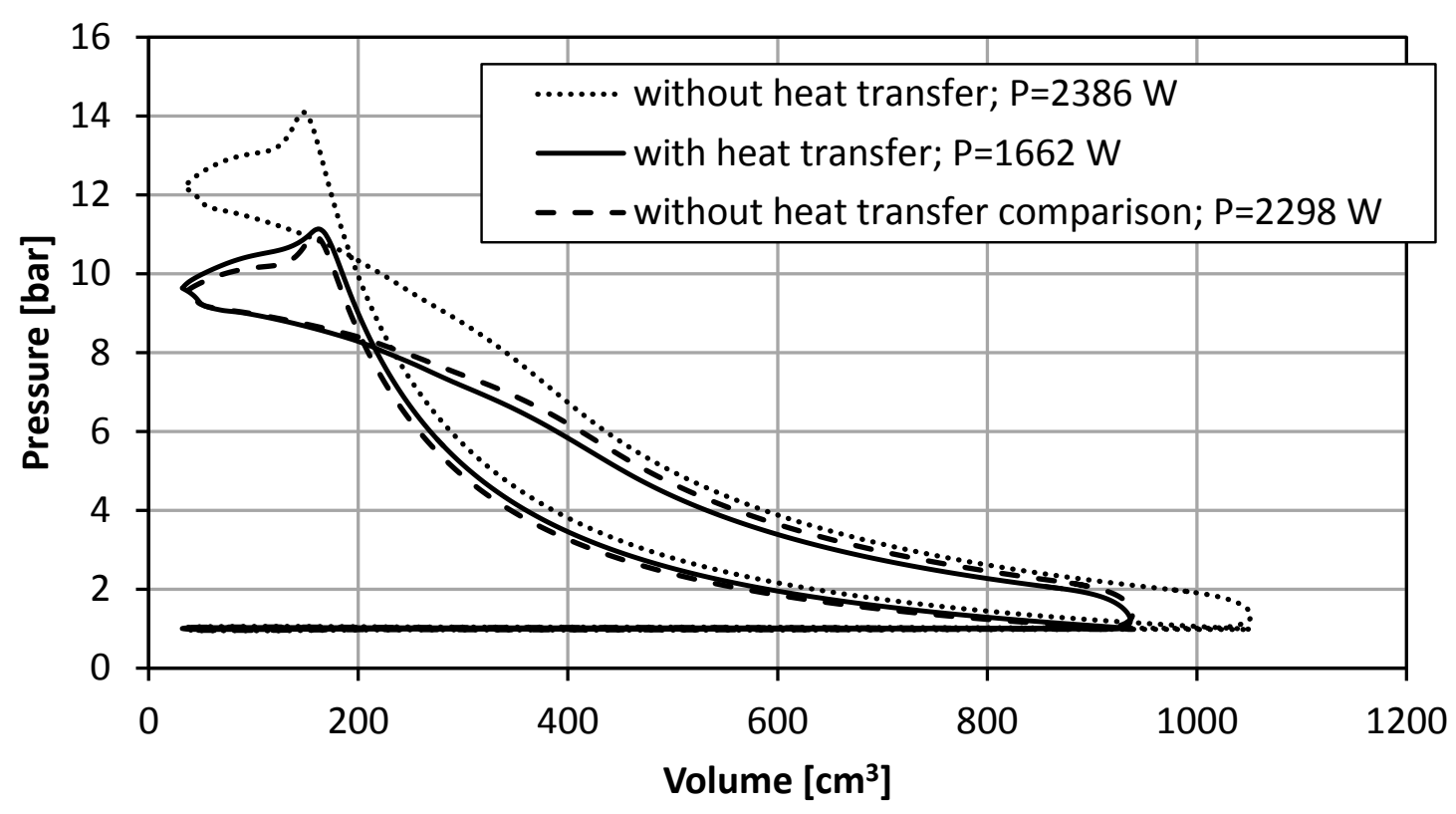

Figure 17. pV diagram of the cycle with and without the heat transfer

\subsection{Mechanical losses}

571

572

573

574

575

576

577

For a warmed up machine, mechanical losses would mainly depend on machine speed and piston stroke. Machine rotary speed was fixed because it was supposed that machine is directly coupled to the IC engine and its speed was fixed for the selected operative point to $2623 \mathrm{rpm}$. Thereby, for all other parameters defined, mechanical losses would depend on piston stroke. Figure 18 shows this dependency and it can be seen that the power of mechanical losses is in the same order of magnitude than the recuperated power.

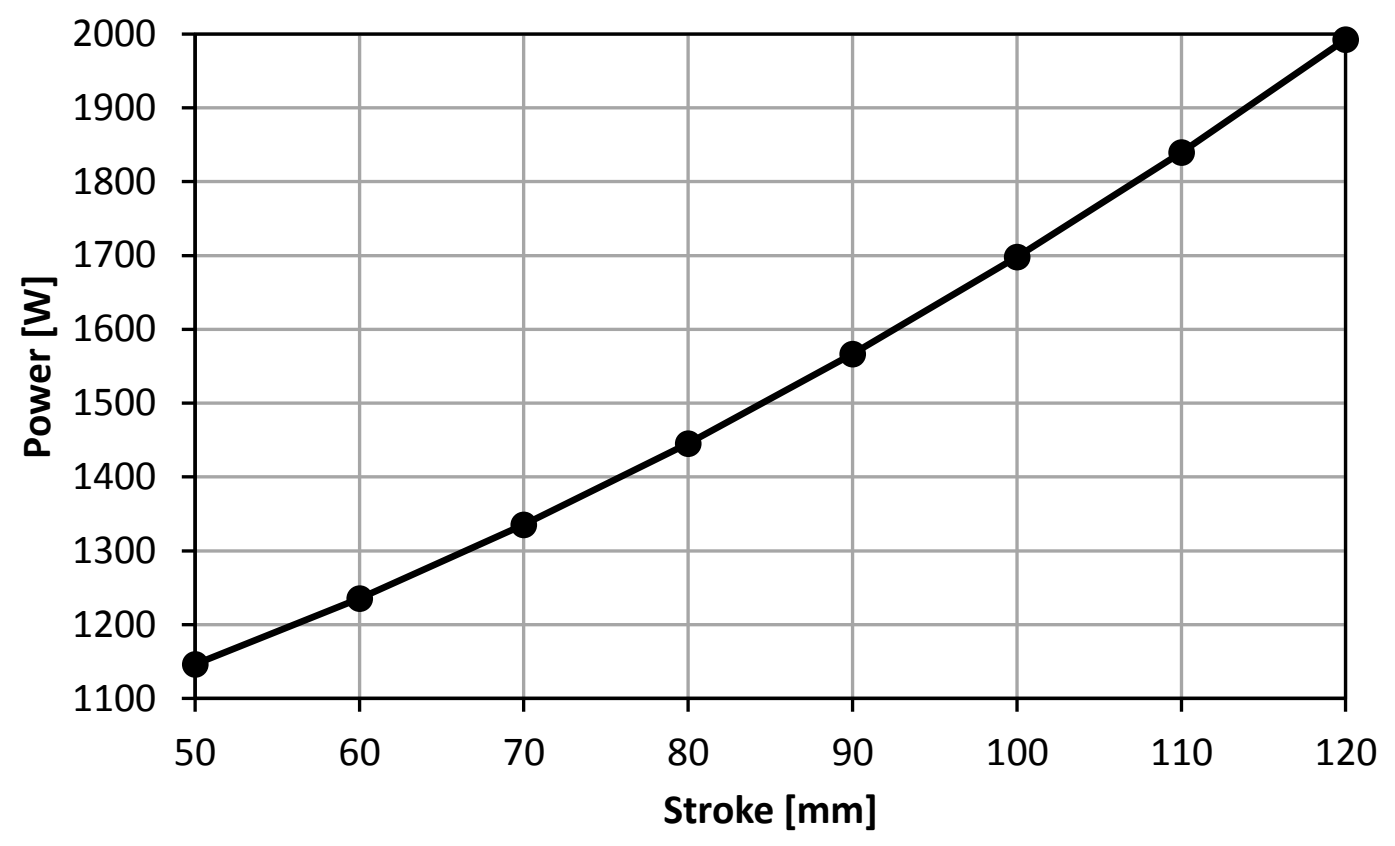

Figure 18. Power of mechanical losses as a function of piston stroke 
Figure 19 shows the calculated friction mean effective pressure (fmep) for each component from the equations for a piston stroke $80 \mathrm{~mm}$. The equations for calculation of each component were taken from the literature [35]. Total calculated fmep was 68.67 $\mathrm{kPa}$. This friction mean effective pressure produces a calculated power of mechanical losses of $1445 \mathrm{~W}$. This power represents $40.59 \%$ of the energy generated by positive work loop for the reference model $(3560 \mathrm{~W}$ for the model with reed valve and without heat transfer). These high mechanical losses would waste almost all the power obtained by the indicated cycle (1662 W obtained by the model with heat transfer).

It can be seen that piston hydrodynamic friction, friction in main bearings and mixed friction in the valvetrain represent the most significant losses. These are the main losses that should be addressed in order to reduce the total mechanical losses.

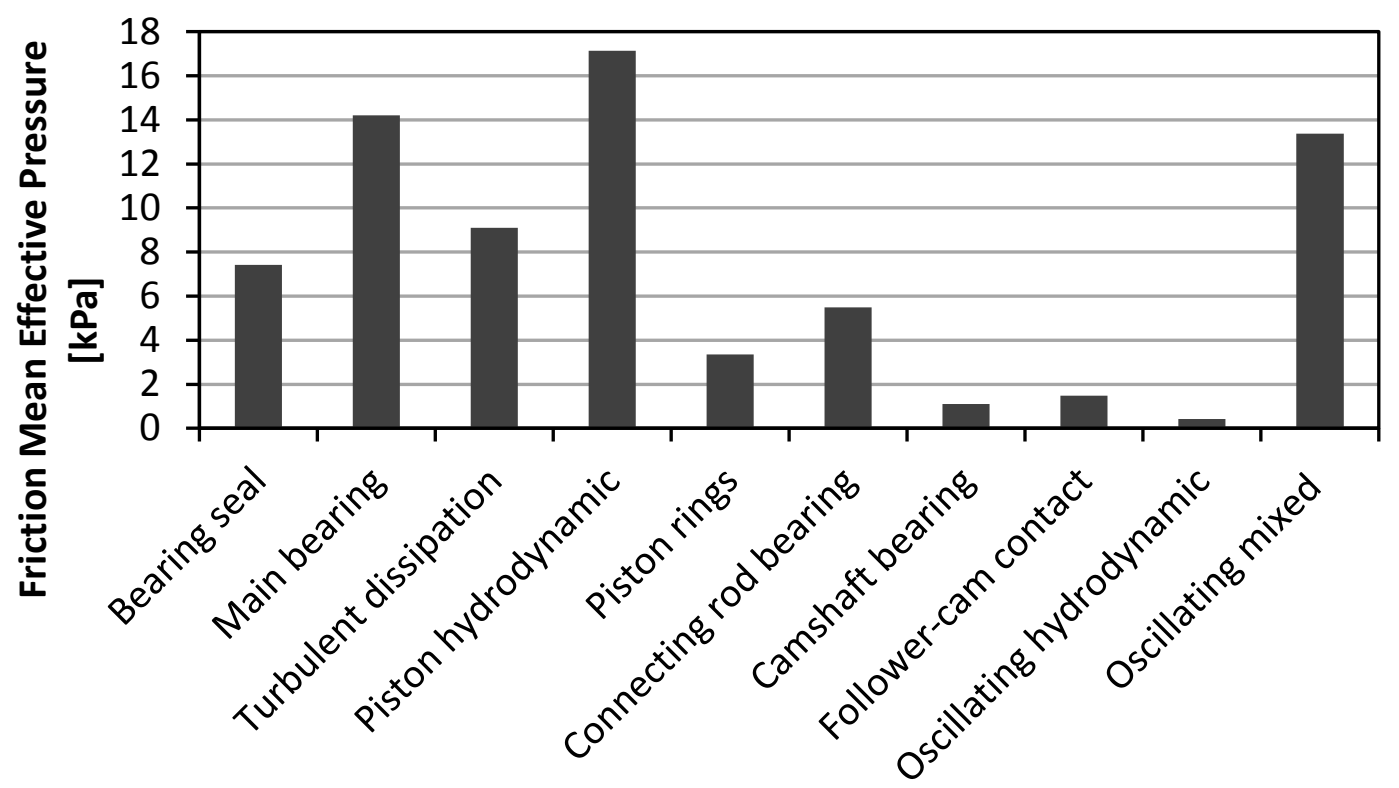

Figure 19. Friction mean effective pressure of each machine component; Stroke

\subsection{Indirect losses}

\section{Exhaust backpressure pumping losses}

By considering the heat transferred through the heat exchanger in the model, temperatures and pressures at the inlet and the outlet of heat exchanger in the gas side can be estimated. By using these values, mean gas density was then calculated to be $\rho=0.439$ $\mathrm{kg} / \mathrm{m}^{3}$ and pressure drop $\Delta \mathrm{p}=1.45 \mathrm{kPa}$ was calculated from the heat exchanger model. Power loss was calculated to be approximately $89 \mathrm{~W}$.

\section{Additional weight}

Waste heat recovery system is composed of two main parts: heat exchanger and compression-expansion piston machine. Apart from these two main elements other possible components that could increase the vehicle weight could be: tubes that connect the heat exchanger and piston machine, control system, clutch to detach the machine from the engine when the machine cannot produce power, pulleys and belt or other system to 
607

connect the machine with the engine etc. Nevertheless, probably the biggest part of the system weight goes on two main components. Heat exchanger prototype exists so it was possible to measure its weight. The heat exchanger that was used in this study weighted $10 \mathrm{~kg}$. It should be noted that this is a prototype of the heat exchanger and it is reasonable to believe that a production version would be lighter. As no prototype of the piston machine was made, its weight had to be estimated. The weight of several aluminium internal combustion engines with different displacement and cylinder number was used to estimate the weight per volume ratio of these engines. The engines that were used as a sample were: 1 cylinder $600 \mathrm{~cm}^{3}$ motorcycle engine, 10 cylinder $5000 \mathrm{~cm}^{3}$ car engine and 4 cylinder $2000 \mathrm{~cm}^{3}$ car engine. They weight per displaced volume ratio was in the range $45-48 \mathrm{~kg} / \mathrm{dm}^{3}$. As displaced volume of the WHR machine is $0.936 \mathrm{dm}^{3}$ for the $80 \mathrm{~mm}$ stroke, machine weight was estimated at $43 \mathrm{~kg}$. As a first approximation, the total WHR system weight was estimated at $55 \mathrm{~kg}$.

Ford Mondeo was used as an example of the vehicle. Parameters that are needed for calculation of additional engine power due to the weigh increment are given in Table 5 .

\begin{tabular}{|c|c|}
\hline Parameter & Value \\
\hline$f$ & 0.01 \\
\hline$\eta_{T R}$ & 0.9 \\
\hline $\mathrm{v}_{\mathrm{veh}}[\mathrm{km} / \mathrm{h}]$ & 120 \\
\hline
\end{tabular}

Table 5. Parameters for calculation of engine power to compensate vehicle

$$
\text { weight }
$$

It was estimated that engine has to make $200 \mathrm{~W}$ more to compensate the additional weight.

\section{Results}

The summary of the proposed system positive and negative contributions is represented in Application of the WHR in a passenger car is limited by available space, regulations that prevent use of certain fluids and cost. For these reasons, Brayton cycle seems as a promising solution because it offers compact and simple system with lower costs that uses air as a working fluid. Additionally, a volumetric compression-expansion machine has been considered for the cycle increasing the compactness and the simplicity of the proposed system. Although it seems as a promising solution it was not much studied in the scientific circles. This lack of publications and mentioned advantages of the system were the main motivation for this study. However, the results of this study show that practical realisation of the cycle is not very viable because the system would probably work only in the engine operating points with high exhaust gas energy, .such as highway driving, Even then the recuperated power would be too small to justify the complexity and additional cost of the system.

. It is evident that losses overcome the cycle positive work. As can be seen in this table, the power obtained from the positive work loop is totally cancelled by the power losses of the considered sources. In order to design a viable system, high pressure 


\begin{tabular}{|c|c|c|c|c|}
\hline \multirow{4}{*}{ Positive } & $\begin{array}{c}\text { Contribution } \\
\text { model without heat } \\
\text { transfer with reed valve } \\
\text { as HP outlet valve }\end{array}$ & $\begin{array}{c}\text { Power } \\
{[\mathbf{W}]}\end{array}$ & $\begin{array}{c}\text { Percentage } \\
\text { with respect to } \\
\text { positive loop } \\
{[\%]}\end{array}$ & $\begin{array}{c}\text { Percentage } \\
\text { with respect to } \\
\text { available heat } \\
\text { power [\%] }\end{array}$ \\
\hline \multirow{4}{*}{ Negative } & HP negative work loop & -1032 & +100 & +18.4 \\
\cline { 2 - 5 } & LP negative work loop & -142 & -4 & -5.3 \\
\cline { 2 - 6 } & Heat transfer losses & -724 & -20.3 & -0.7 \\
\cline { 2 - 6 } & Mechanical losses & -1445 & -40.6 & -3.7 \\
\hline \multicolumn{2}{|c|}{ Recovered Mechanical Power } & $\mathbf{2 1 7}$ & $\mathbf{+ 6 . 1}$ & $\mathbf{+ 1 . 1}$ \\
\hline \multirow{2}{*}{$\begin{array}{c}\text { Indirect } \\
\text { losses }\end{array}$} & Additional back pressure & -89 & -2.5 & -0.5 \\
\cline { 2 - 6 } & Additional weight & -200 & -5.6 & -1 \\
\hline
\end{tabular}

\section{Table 6. Cycle power summary}

By considering the indicated power, $3560 \mathrm{~W}$ are recuperated in the ideal positive work loop. It means an $18 \%$ of the total heat power available in the exhaust gasses. This percentage is much related to the heat transfer efficiency of the heat exchanger. The heat exchanger model validation was done by tests performed at constant air mass flow while the air flow in the alternating piston machine is very pulsating. Pulsating flow could be important for the heat transfer. Many researchers investigated the effect of pulsation on heat transfer. Different studies [37-39] showed that, depending on conditions, pulsating flow could increase the heat transfer coefficient compared to constant flow. Heat exchanger efficiency directly affects the recuperated power so it is very important to have a good design of this element to improve its efficiency.

On the other hand, $1032 \mathrm{~W}$ (29\% of the positive work loop power) are lost in the HP negative loop, $142 \mathrm{~W}$ ( $4 \%$ of the positive work loop power) are lost in the LP negative loop and $724 \mathrm{~W}$ ( $20.3 \%$ of the positive work loop power) are lost due to heat losses in the expander. It means that by considering positive and negative loops and expander heat losses, the power recuperated by the reed valve compression-expansion machine is estimated to $1662 \mathrm{~W}$. Considering these values, the highest contribution to the expander power loss comes from the HP negative loop. In order to reduce this loss, other valve characteristics with higher effective areas should be considered in order to reduce the power loss produced during the breathing process of the machine.

The model of mechanical losses estimates that $1445 \mathrm{~W}$ of crankshaft power (40.6\% of the positive work loop power) would be spent on friction. This amount of mechanical losses would effectively make the cycle non-viable, as it uses almost all the recuperated power that was left after applying the heat transfer model. The model of mechanical losses used empirical equations that were obtained from the measurements of mechanical losses in internal combustion engines. As in the Brayton cycle machine there 
672 is no combustion, pressures are much lower than in the ICE. Thereby, stress on the 673 machine parts is much lower. Machine parts that would be less loaded are primarily 674 piston, piston rings, connecting rod, connecting rod bearings, crankshaft and crankshaft 675 bearings. A big part of mechanical losses comes exactly from those parts. Piston 676 hydrodynamic friction losses and friction losses in the main bearings make for almost $67742 \%$ of all mechanical losses. If piston and main bearings are dimensioned lighter, it is 678 reasonable to believe that mechanical losses could be less than what was estimated by the 679 model that was fitted with the ICE experimental values. Considering all these 680 contributions, positive and negative loops, heat transfer losses and mechanical losses, the 681 total recovered mechanical power in the compression-expansion machine is reduced to $682217 \mathrm{~W}$. It means only $1.1 \%$ of the total heat power available in the exhaust gasses.

Finally, other indirect power losses, external to the volumetric machine, such as the additional back pressure in the exhaust line introduced by the heat exchanger or the additional weight of the Brayton cycle have been considered. They have a lower contribution to the global power losses but they will produce an unviable system for the waste heat recovery system, cancelling out all the power obtained from the volumetric machine, as Table 6 shows.

\section{Conclusions}

690

Application of the WHR in a passenger car is limited by available space, regulations that prevent use of certain fluids and cost. For these reasons, Brayton cycle seems as a promising solution because it offers compact and simple system with lower costs that uses air as a working fluid. Additionally, a volumetric compression-expansion machine has been considered for the cycle increasing the compactness and the simplicity of the proposed system. Although it seems as a promising solution it was not much studied in the scientific circles. This lack of publications and mentioned advantages of the system were the main motivation for this study. However, the results of this study show that practical realisation of the cycle is not very viable because the system would probably work only in the engine operating points with high exhaust gas energy, .such as highway driving, Even then the recuperated power would be too small to justify the complexity and additional cost of the system.

Considering the results summarized in Table 6, it seems hard to imagine that the proposed cycle could be made viable. Nevertheless, some power losses sources of the Brayton cycle system were identified as the most important losses sources and they deserve further study. These power losses sources are the efficiency of the heat exchanger, the HP negative loop and the mechanical losses of the compression-expansion machine. Regarding the efficiency of the heat exchanger and also thermodynamic irreversibilities, only $18 \%$ of the total heat power available in the exhaust gasses is recuperated in the positive work loop of the machine. A redesign of this heat exchanger in order to improve its efficiency is mandatory to increase this value. Regarding the HP negative loop power losses, they represent $29 \%$ of the recovered power in the positive work loop of the machine. They are produced due to the short time for the air movement between the volumetric machine and the heat exchanger. To improve this value, a redesign of the valve system should be considered in order to increase the effective area of these valves to improve this process. Finally, the mechanical losses of the machine represent $40.6 \%$ of the recovered power in the positive work loop of the machine. In order to reduce this 
717 value, a redesign of the lubrication system should be considered to reduce the mechanical 718 losses of the machine.

719 
721

722

723

724

725

726

727

728

729

730

731

732

733

734

735

736

737

738

739

740

741

742

743

744

745

746

747

748

749

750

751

752

753

754

755

756

757

758

759

760

761

762

763

[1] Comission E. Reducing $\mathrm{CO} 2$ emissions from passenger cars n.d. https://ec.europa.eu/clima/policies/transport/vehicles/cars/index_en.htm.

[2] Fergusson M. An analysis of carmaker progress towards EU CO2 targets in 2014. 2015.

[3] Toom R. Waste Heat Regeneration systems for internal combustion engines. Engine Expo, 2007.

[4] Luján JM, Climent H, Dolz V, Moratal A, Borges-Alejo J, Soukeur Z. Potential of exhaust heat recovery for intake charge heating in a diesel engine transient operation at cold conditions. Appl Therm Eng 2016;105:501-8. doi:10.1016/j.applthermaleng.2016.03.028.

[5] Novella R, Dolz V, Mart??n J, Royo-Pascual L. Thermodynamic analysis of an absorption refrigeration system used to cool down the intake air in an Internal Combustion Engine. Appl Therm Eng 2017;111:257-70. doi:10.1016/j.applthermaleng.2016.09.084.

[6] Hatami M, Jafaryar M, Ganji DD, Gorji-Bandpy M. Optimization of finned-tube heat exchangers for diesel exhaust waste heat recovery using CFD and CCD techniques. Int Commun Heat Mass Transf 2014;57:254-63. doi:10.1016/j.icheatmasstransfer.2014.08.015.

[7] Hatami M, Ganji DD, Gorji-Bandpy M. Experimental and thermodynamical analyses of the diesel exhaust vortex generator heat exchanger for optimizing its operating condition. Appl Therm Eng 2015;75:580-91. doi:10.1016/j.applthermaleng.2014.09.058.

[8] Hossain SN, Bari S. Waste heat recovery from the exhaust of a diesel generator using Rankine Cycle. Energy Convers Manag 2013;75:141-51. doi:10.1016/j.enconman.2013.06.009.

[9] Galindo J, Ruiz S, Dolz V, Royo-Pascual L. Advanced exergy analysis for a bottoming organic rankine cycle coupled to an internal combustion engine. Energy Convers Manag 2016;126:217-27. doi:10.1016/j.enconman.2016.07.080.

[10] Galindo J, Climent H, Dolz V, Royo-Pascual L. Multi-objective optimization of a bottoming Organic Rankine Cycle (ORC) of gasoline engine using swash-plate expander. Energy Convers Manag 2016;126:1054-65. doi:10.1016/j.enconman.2016.08.053.

[11] Dolz V, Novella R, García A, Sánchez J. HD Diesel engine equipped with a bottoming Rankine cycle as a waste heat recovery system. Part 1: Study and analysis of the waste heat energy. Appl Therm Eng 2012;36:269-78.

[12] Serrano JR, Dolz V, Novella R, García A. HD Diesel engine equipped with a bottoming Rankine cycle as a waste heat recovery system. Part 2: Evaluation of alternative solutions. Appl Therm Eng 2012;36:279-87.

[13] Galindo J, Dolz V, Royo-Pascual L, Haller R, Melis J. Modeling and experimental validation of a volumetric expander suitable for waste heat recovery from an automotive internal combustion engine using an organic Rankine cycle with ethanol. Energies 2016;9. doi:10.3390/en9040279.

[14] Luján JM, Serrano JR, Dolz V, Sánchez J. Model of the expansion process for 
R245fa in an Organic Rankine Cycle (ORC). Appl Therm Eng 2012;40:248-57.

[15] Crane DT, Jackson GS. Optimization of cross flow heat exchangers for thermoelectric waste heat recovery. Energy Convers Manag 2004;45:1565-82. doi:10.1016/j.enconman.2003.09.003.

[16] Wang T, Luan W, Liu T, Tu S-T, Yan J. Performance enhancement of thermoelectric waste heat recovery system by using metal foam inserts. Energy Convers Manag 2016;124:13-9. doi:10.1016/j.enconman.2016.07.006.

[17] Demir ME, Dincer I. Performance assessment of a thermoelectric generator applied to exhaust waste heat recovery. Appl Therm Eng 2017;120:694-707. doi:10.1016/j.applthermaleng.2017.03.052.

[18] Stobart R, Wijewardane MA, Yang Z. Comprehensive analysis of thermoelectric generation systems for automotive applications. Appl Therm Eng 2017;112:143344. doi:10.1016/j.applthermaleng.2016.09.121.

[19] Wang K, He YL, Zhu HH. Integration between supercritical CO2 Brayton cycles and molten salt solar power towers: A review and a comprehensive comparison of different cycle layouts. Appl Energy 2017;195:819-36. doi:10.1016/j.apenergy.2017.03.099.

[20] Battisti FG, Cardemil JM, da Silva AK. A multivariable optimization of a Brayton power cycle operating with CO2 as working fluid. Energy 2016;112:908-16. doi:10.1016/j.energy.2016.06.118.

[21] Luu MT, Milani D, McNaughton R, Abbas A. Analysis for flexible operation of supercritical $\mathrm{CO} 2$ Brayton cycle integrated with solar thermal systems. Energy 2017;124:752-71. doi:10.1016/j.energy.2017.02.040.

[22] Chen L, Ni D, Zhang Z, Sun F. Exergetic performance optimization for new combined intercooled regenerative Brayton and inverse Brayton cycles. Appl Therm Eng 2016;102:447-53. doi:10.1016/j.applthermaleng.2016.03.058.

[23] Goodarzi M. Usefulness analysis on regenerator and heat exchanger in Brayton \& inverse Brayton cycles at moderate pressure ratio operation. Energy Convers Manag 2016;126:982-90. doi:10.1016/j.enconman.2016.08.058.

[24] Daabo AM, Mahmoud S, Al-Dadah RK, Al Jubori AM, Bhar Ennil A. Numerical analysis of small scale axial and radial turbines for solar powered Brayton cycle application. Appl Therm Eng 2017;120:672-93. doi:10.1016/j.applthermaleng.2017.03.125.

[25] Liu X, Gong G, Wu Y, Li H. Thermal performance analysis of Brayton cycle with waste heat recovery boiler for diesel engines of offshore oil production facilities. Appl Therm Eng 2016;107:320-8. doi:10.1016/j.applthermaleng.2016.05.066.

[26] Deng B, Tang Q, Li M. Study on the steam-assisted Brayton air cycle for exhaust heat recovery of internal combustion engine. Appl Therm Eng 2017;125:714-26. doi:10.1016/j.applthermaleng.2017.07.039.

[27] Galindo J, Serrano J, Dolz V, Kleut P. Brayton cycle for internal combustion engine exhaust gas waste heat recovery. Adv Mech Eng 2015;7. doi:10.1177/1687814015590314.

[28] Idel'chik IE, Steinberg MO. Handbook of Hydraulic Resistance. Begell House; 1996. 
808 [29] Heywood JB. Internal Combustion Engine Fundamentals. vol. 21. 1988.

809 [30] Payri F, Desantes JM. Motores de combustión interna alternativos. 2013.

810 [31] Blair GP. Design and Simulation of Four-stroke Engines. Society of Automotive $811 \quad$ Engineers; 1999.

812 [32] Fleck R, Cartwright A, Thornhill D. Mathematical Modelling of Reed Valve 813 Behaviour in High Speed Two-Stroke Engines 1997. doi:10.4271/972738.

814 [33] Blair GP. Design and Simulation of Two-stroke Engines. Society of Automotive 815 Engineers; 1996.

816 [34] Annand WJD, Pinfold D. Heat Transfer in the Cylinder of a Motored Reciprocating

[35] Sandoval D, Heywood JB. An Improved Friction Model for Spark-Ignition Engines. SAE Tech Pap 2003. doi:10.4271/2003-01-0725.

820 [36] Kakaç S, Liu H, Pramuanjaroenkij A. Heat Exchangers: Selection, Rating, and Thermal Design, Second Edition. Taylor \& Francis; 2002.

[37] Zohir AE, Habib MA, Attya AM, Eid AI. An experimental investigation of heat transfer to pulsating pipe air flow with different amplitudes. Heat Mass Transf 2006;42:625-35. doi:10.1007/s00231-005-0036-z.

[38] Habib MA, Attya AM, Eid AI, Aly AZ. Convective heat transfer characteristics of laminar pulsating pipe air flow. Heat Mass Transf 2002;38:221-32. doi:10.1007/s002310100206.

[39] Habib MA, Attya AM, Said SAM, Eid AI, Aly AZ. Heat transfer characteristics and Nusselt number correlation of turbulent pulsating pipe air flows. Heat Mass Transf 2004;40:307-18. doi:10.1007/s00231-003-0456-6. 